Journal for ImmunoTherapy of Cancer

\title{
The Society for Immunotherapy of Cancer (SITC) clinical practice guideline on immunotherapy for the treatment of acute leukemia
}

\begin{abstract}
Michael M Boyiadzis, ${ }^{1}$ Ivan Aksentijevich, ${ }^{2}$ Daniel A Arber, ${ }^{3}$ John Barrett, ${ }^{4}$ Renier J Brentjens, ${ }^{5}$ Jill Brufsky, ${ }^{1}$ Jorge Cortes, ${ }^{6}$ Marcos De Lima, ${ }^{7}$ Stephen J Forman, ${ }^{8}$ Ephraim J Fuchs, ${ }^{9}$ Linda J Fukas, ${ }^{10}$ Steven D Gore, ${ }^{11}$ Mark R Litzow, ${ }^{12}$ Jeffrey S Miller, ${ }^{13}$ John M Pagel, ${ }^{14}$ Edmund K Waller, ${ }^{15}$ Martin S Tallman ${ }^{5}$
\end{abstract}

To cite: Boyiadzis MM, Aksentijevich I, Arber DA, et al. The Society for Immunotherapy of Cancer (SITC) clinical practice guideline on immunotherapy for the treatment of acute leukemia. Journal for ImmunoTherapy of Cancer 2020;8:e000810. doi:10.1136/jitc-2020-000810

- Additional material is published online only. To view please visit the journal online (http://dx.doi.org/10.1136/jitc2020-000810).

Accepted 17 July 2020

Check for updates

(c) Author(s) (or their employer(s)) 2020. Re-use permitted under CC BY-NC. No commercial re-use. See rights and permissions. Published by BMJ.

For numbered affiliations see end of article.

Correspondence to Dr Michael M Boyiadzis; boyiadzism@upmc.edu

\section{ABSTRACT}

Acute leukemia is a constellation of rapidly progressing diseases that affect a wide range of patients regardless of age or gender. Traditional treatment options for patients with acute leukemia include chemotherapy and hematopoietic cell transplantation. The advent of cancer immunotherapy has had a significant impact on acute leukemia treatment. Novel immunotherapeutic agents including antibody-drug conjugates, bispecific $T$ cell engagers, and chimeric antigen receptor T cell therapies have efficacy and have recently been approved by the US Food and Drug Administration (FDA) for the treatment of patients with acute leukemia. The Society for Immunotherapy of Cancer (SITC) convened a panel of experts to develop a clinical practice guideline composed of consensus recommendations on immunotherapy for the treatment of acute lymphoblastic leukemia and acute myeloid leukemia.

\section{INTRODUCTION}

The acute leukemias, including acute lymphoblastic leukemia (ALL) and acute myeloid leukemia (AML), are rapidly progressing forms of leukemias defined by high percentages of blasts in the blood and bone marrow and by the predominant lineages of malignant cells. ${ }^{1}$ In 2020, an estimated 26,090 cases of acute leukemias will be diagnosed in the US and 12,700 deaths are anticipated. ${ }^{2}$ In children, leukemia is the most common hematologic malignancy, and the incidence of childhood leukemia has steadily increased every year. ${ }^{3}$ Advances in molecular diagnostics over the past several decades have further defined multiple disease subtypes, differentiated by the presence of specific genetic markers, which have informed riskbased treatment paradigms to reduce toxicity in low-risk patients while pursuing more aggressive therapies for those with a high risk of relapse. $^{4-7}$

Standard treatment paradigms for acute leukemia have centered on high-intensity induction chemotherapy to achieve complete remission (CR) followed by allogeneic hematopoietic cell transplant (allo-HCT) in certain patients $^{8-10}$ to eradicate residual disease through the "graft versus leukemia" effect mediated by the donor's immune cells. ${ }^{11-13}$ However, allo-HCT is not indicated for all patients and a major ongoing challenge in the field is that few chemotherapy-based options are effective following relapse after allo-HCT or for patients who develop chemotherapyrefractory disease. ${ }^{1314}$

Immunotherapeutic approaches have dramatically altered the treatment landscape across a variety of disease settings, including hematological cancers. In recent years, novel agents including monoclonal antibodies, bispecific antibodies, antibodydrug conjugates (ADCs), and engineered chimeric antigen receptor (CAR) T cells have been approved by the US Food and Drug Administration (FDA), offering additional options beyond standard regimens and deep and durable responses in some patients. ${ }^{15-18}$ Although ADCs may not be classified as a traditional form of immunotherapy, there is evidence of immunomodulatory activity by these agents. ${ }^{19}$

While immunotherapies for acute leukemia have demonstrated efficacy in a number of large-scale, randomized trials, ${ }^{15} 2021$ clinical experience with some of these novel agents is still somewhat limited. To support the oncology community and provide expert, evidence-based recommendations, the 
Society for Immunotherapy of Cancer (SITC) published consensus recommendations in December 2016 on the role of immunotherapy in the treatment of hematological malignancies. ${ }^{22}$ Since 2016, however, rapid advances in the field have brought about a wider array of immunotherapy-based treatment options for each of the individual disease states discussed in the original guidelines: acute leukemia, lymphoma, and multiple myeloma. Thus, the SITC Cancer Immunotherapy GuidelinesHematologic Malignancies Subcommittee determined that stand-alone guidelines are needed. To form up-todate recommendations on the use of immunotherapy for the treatment of patients with acute leukemia, SITC convened a panel of experts to develop a new clinical practice guideline. This publication represents an update to the previously published consensus statement based on a more recent assessment of the peer-reviewed literature and the clinical experience of expert panel participants. These recommendations are not intended to supplant sound clinical judgment but rather to provide clinicians with the most current thinking on how experts integrate immunotherapy into the treatment of patients with acute leukemia.

\section{METHODS}

\section{SITC Acute Leukemia Immunotherapy Guideline Expert Panel}

The SITC Acute Leukemia Guideline Expert Panel consisted of 17 participants, including medical oncologists, hematologists, a hematopathologist, a leukemia research nurse, and a patient advocate. Every clinical Expert Panel member reported previous experience/ knowledge regarding the use of immunotherapy for the treatment of patients with leukemia. The panel members met in person and communicated regularly via email and teleconference. In addition, they completed a survey (see online supplementary file 1) addressing clinical topics concerning the use of cancer immunotherapy for the treatment of patients with acute leukemia, which helped form the basis for these recommendations.

\section{Consensus statement policy}

The Institute of Medicine's (IOM) Standards for Developing Trustworthy Clinical Practice Guidelines were used as a model to develop the consensus recommendations in this manuscript. IOM standards dictate that guideline development be led by a multidisciplinary team using a transparent process where both funding sources and conflicts of interest are readily reported. Recommendations are based on literature evidence, where possible, and clinical experience, where appropriate. ${ }^{23}$ For transparency, a draft of this consensus statement was made publicly available for comment after journal submission. All comments were considered for inclusion into the final manuscript. This consensus statement is intended to provide guidance and is not a substitute for the professional judgment of individual treating physicians.

\section{Evidence and consensus ratings}

Recommendations were derived from evidence within the published literature along with responses to a clinical questionnaire that addressed current practices in the use or recommendation for use of immunotherapy agents (online supplementary file 1). SITC Cancer Immunotherapy Guidelines provide recommendations based on peer-reviewed literature and consensus within the expert panel. Consensus was defined as $\geq 75 \%$ agreement among expert panel members.

\section{Conflicts of interest policy}

As per SITC policy, expert panel members managed potential competing interests through disclosure of all financial relationships that might result in actual, potential, or perceived conflicts of interest. No commercial funding was provided to support the expert panel, literature review, or the preparation of this manuscript.

\section{Literature review process}

The MEDLINE database was used to search the scientific literature for current therapies related to acute leukemia and immunotherapy, including clinical trials, metaanalyses, practice guidelines, and research in humans.

The search terms included among others "acute lymphoblastic leukemia," "acute myeloid leukemia," "blinatumomab," "inotuzumab ozogamicin," "tisagenlecleucel," "CAR T AND leukemia," "gemtuzumab ozogamicin," "immunotherapy AND leukemia," and "immunotherapy toxicity." Manuscripts retrieved by the search were screened to include only papers with clinically accurate and relevant information and to remove duplicate articles from independent searches. The reference library was supplemented with additional articles identified by the panel as appropriate and necessary for a comprehensive literature review, resulting in a final bibliography of 141 manuscripts.

\section{DIAGNOSTICS PRIOR TO IMMUNOTHERAPY FOR NEWLY DIAGNOSED PATIENTS WITH ACUTE LEUKEMIA}

A number of clinical guidelines have been developed for the workup and diagnosis of acute leukemia. Initial workup provides disease classification, risk stratification, and a better understanding of both disease biology and potential treatment options. ${ }^{15} 6{ }^{24-26}$ Selection of appropriate diagnostics to initiate immunotherapies is under investigation. Only in a select few situations has consensus been achieved on how to determine whether a patient is a strong candidate for immunotherapy. Further, if a patient is eligible for two different immunotherapies, it is challenging to identify the treatment option that will provide maximal benefit. Potential diagnostic evaluations for patients with acute leukemia being considered for immunotherapy are discussed below.

A number of diagnostics are available for the initial workup of a patient suspected to have acute leukemia. Workup typically includes history and physical 
examination, complete blood counts (CBC) and leucocyte differential counts, platelets, electrolytes, liver function tests, prothrombin time (PT), partial thromboplastin time (PTT), international normalized ratio (INR), fibrinogen, lactate dehydrogenase (LDH), uric acid, human leucocyte antigen (HLA) typing for patients who are candidates for allo-HCT, chest X-ray and CT/MRI scans if clinically indicated, echocardiogram, and a lumbar puncture if neurological symptoms are present. ${ }^{562427}$ Bone marrow biopsy/aspirate with cytogenetics (karyotype and fluorescence in situ hybridization (FISH)), immunophenotyping, and molecular studies including next generation sequencing, are performed to diagnose and classify disease characteristics. Cytochemical studies can also help to differentiate between ALL and AML, but do not traditionally replace immunophenotyping. Appropriate sensitivity of all assessment techniques must be verified to ensure that measurable/minimal residual disease (MRD) status can also be assessed in future management stages. $^{24-26}$

Acute leukemia can be associated with a variety of genetic mutations that may serve as markers for MRD or be targetable with drugs. ALL can be associated with a variety of genetic mutations. The American Society of Clinical Oncology/College of American Pathologists/ American Society of Hematology (ASCO/CAP/ASH) guidelines for the workup of acute leukemia recommend a number of genetic tests to identify different mutations. A summary of the recommended molecular tests for ALL and AML is provided in table 1.

While molecular characterization may identify actionable mutations for targeted therapies such as tyrosine kinase inhibitors, cell surface markers may be used to identify potential targets for immunotherapies. The National Comprehensive Cancer Network (NCCN) and the European Society for Medical Oncology (ESMO) guidelines, in addition to molecular testing, also recommend assaying for specific cell markers, such as CD19, CD20, and CD22 for ALL and CD33 for AML to assess eligibility for potential antibody-based therapies. ${ }^{56}$ Importantly, however, current clinical pathology laboratories for CD19 and CD22 expression report only the presence or percent expression, which is often not an accurate representation of the number of molecules or the presence of subpopulations of leukemia cells that lack these markers. ${ }^{28}$ Subpopulations of CD19-negative or CD22-negative or low-expression leukemia cells may play an important role in eventual relapse. A retrospective analysis of flow cytometry archives found profound heterogeneity in CD22 and CD19 expression across 628 B-ALL cases. ${ }^{29}$ Although such analyses remain strictly for research use at this point, with the increasing use of CD19-specific or CD22-specific immunotherapies, the heterogeneity in cell surface marker expression is likely to become an important consideration in the future.

Certain FDA-approved immunotherapies for the treatment of patients with acute leukemia require specific disease characteristics for eligibility. For example,
Table 1 ASCO/CAP/ASH recommended genetic tests for $\mathrm{ALL}$ and $\mathrm{AML}^{6}$

\begin{tabular}{ll}
\hline Disease state & Recommended tests \\
\hline ALL* $^{*}(9 ; 22)(\mathrm{q} 34.1 ; \mathrm{q} 11.2) ;$ PAX5 \\
& CRLF2; JAK1 \\
& BCR-ABL1; JAK2 \\
& KMT2A (MLL); IKZF1 (for B-ALL) \\
& CRLF2 overexpression (for B-ALL) \\
& NOTCH1 and/or FBXW7 (for T-ALL) \\
AML (pediatric and & FLT3-ITD; IDH1 \\
adult)†‡ & NPM1; IDH2 \\
& $C E B P A ; T E T 2$ \\
& $R U N X 1 ;$ WT1 \\
& $P M L-P A R A ; D N M T 3 A$ \\
& KIT (for CBF AML); TP53 \\
& $R U N X 1-R U N X T 1 / C B F B-M Y H 1$ (for CBF \\
& AML)
\end{tabular}

${ }^{*}$ Characterization of pediatric ALL should also include ETV6RUNX1, iAMP21, and trisomy 4 and 10.

†Results of RUNX1, ASXL1, and TP53 testing are recommended by NCCN guidelines for use in risk stratification and consideration for allo-HCT. ${ }^{5}$

$\ddagger$ Similar recommendations are made by the European Leukemia Net (ELN) group for AML with additional testing for mutations in the epigenetic regulator gene ASXL1 and FLT3-ITD allelic ratios, as well as cell markers. ${ }^{4}$

ALL, acute lymphoblastic leukemia; allo-HCT, allogeneic hematopoietic cell transplant; AML, acute myeloid leukemia; ASCO, American Society of Clinical Oncology; ASH, American Society of Hematology; B-ALL, B-cell acute lymphoblastic leukemia; CAP, College of American Pathologists; CBF, corebinding factor; NCCN, National Comprehensive Cancer Network; T-ALL, T cell acute lymphoblastic leukemia.

gemtuzumab ozogamicin (GO) for the treatment of patients with newly diagnosed or relapsed/refractory (RR) AML requires confirmation of CD33 positivity on malignant cells. ${ }^{30}$ The bispecific antibody blinatumomab that directs CD3 positive T cells to CD19-positive leukemia cells is approved for patients with B-cell ALCL (B-ALL) in first or second complete response (CR) with MRD positivity after induction therapy. ${ }^{16} 2031-35$ Therefore, it is critical to perform phenotypic and molecular characterization of leukemic cells at diagnosis and to assist future MRD status assessment. ${ }^{6242536}$

Several ongoing clinical trials are evaluating the safety and efficacy of emerging immunotherapies directed against specific cell surface markers. For example, MGD006, a dual-affinity $\mathrm{T}$ cell retargeting molecule designed to target CD123-positive cells for recognition and elimination by CD3-expressing $\mathrm{T}$ lymphocytes, is currently being evaluated in a phase I dose-escalation and cohort expansion study in RR AML (NCT02152956). ${ }^{37}$ Additionally, the CD33-directed ADC IMGN779 is undergoing evaluation in a phase I trial (NCT02674763). ${ }^{38}$ 
Table 2 Recommended immunotherapy-centric diagnostic markers for acute leukemia

\begin{tabular}{lll}
\hline Disease type & Marker & $\begin{array}{l}\text { Agents for } \\
\text { consideration }\end{array}$ \\
\hline $\begin{array}{l}\text { Acute lymphoblastic } \\
\text { leukemia }\end{array}$ & CD19 & Blinatumomab \\
& CD19 & $\begin{array}{l}\text { Tisagenlecleucel (patients } \\
\text { aged } \leq 25 \text { years) }\end{array}$ \\
& CD22 & $\begin{array}{l}\text { Inotuzumab ozogamicin } \\
\text { Rituximab }\end{array}$ \\
$\begin{array}{l}\text { Acute myeloid } \\
\text { leukemia }\end{array}$ & CD33 & Gemtuzumab ozogamicin \\
\hline
\end{tabular}

Guidelines for these and other emerging therapies will be discussed in the emerging immunotherapies section of this manuscript. Although many targeted therapies have not yet been FDA approved, experimental diagnostics may assist in referring patients to an appropriate clinical trial. A summary of recommended immunotherapycentric diagnostic markers for approved therapies is in table 2 .

\section{Panel recommendations}

- Cell markers at diagnosis and at the time of disease relapse should be performed to identify potential markers that drugs can be used for treatment.

- Upfront diagnostics for ALL should include the cell markers CD19, CD20, and CD22.

- Upfront diagnostics for AML should include the cell markers CD33 and CD123.

- CD19+ ALL patients may be eligible for blinatumomab or tisagenlecleucel (patients aged $\leq 25$ years).
- CD22+ ALL patients may be eligible for inotuzumab ozogamicin.

- CD33+ AML patients may be eligible for GO.

\section{IMMUNOTHERAPY FOR THE TREATMENT OF PATIENTS WITH \\ ALL}

Treatment of acute leukemia has rapidly evolved since the publication of "The Society for Immunotherapy of Cancer consensus statement on immunotherapy for the treatment of hematologic malignancies" in $2016 .{ }^{22}$ In the intervening years, novel immunotherapeutic approaches, such as ADCs, dual-affinity molecules such as bispecific $\mathrm{T}$ cell engagers (BiTEs), and highly successful CAR T cell therapies, have been approved by FDA and entered the clinic (table 3). Yet, these immunotherapies have specific indications that must be integrated with existing treatment modalities.

\section{Available agents and indications}

The addition of immunotherapies to existing intensive chemotherapy regimens, targeted agents, and allo-HCT has fundamentally altered the treatment landscape for ALL, especially in the relapsed and refractory setting.

Published guidelines from $\mathrm{ESMO}^{26}$ and $\mathrm{NCCN}^{39}$ provide recommendations for remission induction and consolidation therapies, maintenance therapy, central nervous system prophylaxis, and age-adopted protocols for standard treatment regimens.

Currently, three immunotherapies are FDA approved for the treatment of ALL: blinatumomab, inotuzumab ozogamicin, and tisagenlecleucel. Of note, approval for CAR $T$ cell therapies often hinges on data from phase II trials, as was the case for the regulatory decision endorsing the use of tisagenlecleucel for adult patients

Table 3 FDA-approved cancer immunotherapy agents for ALL

\section{Acute lymphoblastic leukemia (ALL)}

\begin{tabular}{|c|c|c|c|c|c|}
\hline Drug & Type & Mechanism & Approval & Indications & References \\
\hline \multirow[t]{2}{*}{ Blinatumomab } & $\begin{array}{l}\text { Bispecific T } \\
\text { cell engager } \\
\text { (BiTE) }\end{array}$ & $\begin{array}{l}\text { A "bispecific" antibody with } \\
\text { recognition domains for CD3 and } \\
\text { CD19 to bring T cells into proximity to } \\
\text { tumor cells to promote cytotoxicity }\end{array}$ & March 2018 & $\begin{array}{l}\text { Adult and pediatric patients with B- } \\
\text { cell precursor } A L L \text { in first or second } \\
\text { complete remission with } M R D \geq 0.1 \%\end{array}$ & 3244130 \\
\hline & & & July 2017 & $\begin{array}{l}\text { Relapsed or refractory B-cell } \\
\text { precursor ALL in adults and children }\end{array}$ & 20131 \\
\hline $\begin{array}{l}\text { Inotuzumab } \\
\text { ozogamicin }\end{array}$ & $\begin{array}{l}\text { Anti-CD22 } \\
\text { antibody- } \\
\text { drug } \\
\text { conjugate }\end{array}$ & $\begin{array}{l}\text { Anti-CD22 antibody conjugated to a } \\
\text { DNA-damaging calicheamicin payload } \\
\text { that causes apoptotic death }\end{array}$ & August 2017 & $\begin{array}{l}\text { Adults with relapsed or refractory B- } \\
\text { cell precursor ALL }\end{array}$ & 2154101 \\
\hline Tisagenlecleucel & $\begin{array}{l}\text { CAR T cell } \\
\text { therapy }\end{array}$ & $\begin{array}{l}\text { Genetically modified autologous T } \\
\text { cells expressing a chimeric receptor } \\
\text { consisting of a CD19-recognition } \\
\text { domain and 4-1BB costimulatory } \\
\text { domain to enhance expansion and } \\
\text { persistence }\end{array}$ & August 2017 & $\begin{array}{l}\text { Patients up to } 25 \text { years of age with } \\
\text { B-cell precursor ALL that is refractory } \\
\text { or in second or later relapse }\end{array}$ & 3344 \\
\hline
\end{tabular}

CAR, chimeric antigen receptor; FDA, Food and Drug Administration; MRD, minimal/measurable residual disease. 
Table 4 Clinical trials using blinatumomab in ALL

\begin{tabular}{|c|c|c|c|c|c|c|}
\hline Trial & $\begin{array}{l}\text { Study } \\
\text { design }\end{array}$ & Patient population & $\begin{array}{l}\text { Enrolled } \\
\text { patients }\end{array}$ & $\begin{array}{l}\text { Primary } \\
\text { endpoint }\end{array}$ & Results & Reference \\
\hline $\begin{array}{l}\text { TOWER } \\
\text { (NCT02013167) }\end{array}$ & $\begin{array}{l}\text { Prospective, } \\
\text { randomized } \\
\text { phase III }\end{array}$ & $\begin{array}{l}\text { Adults with } \mathrm{Ph}-\mathrm{RR} \\
\text { B-ALL }\end{array}$ & 405 & OS & $\begin{array}{l}\text { Median OS } 7.7 \text { months in } \\
\text { blinatumomab group versus } \\
4.0 \text { months in the chemotherapy } \\
\text { group (HR } 0.71 ; 95 \% \mathrm{Cl}, 0.55 \text { to } \\
0.93 ; p=0.01 \text { ) }\end{array}$ & 20 \\
\hline $\begin{array}{l}\text { ALCANTARA } \\
\text { (NCT02000427) }\end{array}$ & $\begin{array}{l}\text { Open-label-, } \\
\text { single-arm } \\
\text { phase II }\end{array}$ & $\begin{array}{l}\text { Adults with } \mathrm{Ph}+\mathrm{RR} \\
\text { B-ALL }\end{array}$ & 45 & CR or CRh & $\begin{array}{l}\text { CR or } \mathrm{CRh} \text { rate } 36 \%(95 \% \mathrm{Cl}, 22 \% \\
\text { to } 51 \%) \text { with } 88 \% \text { MRD- }\end{array}$ & 135 \\
\hline $\begin{array}{l}\text { MT103-205 } \\
\text { (NCT01471782) }\end{array}$ & Phase I/II & Children with RR B-ALL & $\begin{array}{l}93 \text { total (49 } \\
\text { phase I) (44 } \\
\text { phase II) }\end{array}$ & $\begin{array}{l}\text { MTD (phase } \\
\text { I) CR (phase } \\
\text { II) }\end{array}$ & $\begin{array}{l}\text { CR rate } 39 \% \text { ( } 95 \% \text { Cl, } 27 \% \text { to } 51 \%) \\
\text { with } 52 \% \text { MRD- }\end{array}$ & 136 \\
\hline $\begin{array}{l}\text { BLAST } \\
\text { (NCT01207388) }\end{array}$ & $\begin{array}{l}\text { Open-label, } \\
\text { single-arm } \\
\text { phase II }\end{array}$ & $\begin{array}{l}\text { Adults with B- } \\
\text { ALL in first or later } \\
\text { hematological } C R \text { and } \\
\text { persistent or recurrent } \\
\text { MRD } \geq 10^{-3}\end{array}$ & 113 & $\begin{array}{l}\text { Complete } \\
\text { MRD } \\
\text { response }\end{array}$ & $78 \%$ achieved MRD- & 32 \\
\hline
\end{tabular}

B-ALL, B-cell acute lymphoblastic leukemia; CR, complete response; CRh, CR with partial hematologic recovery; FDA, Food and Drug Administration; MRD, minimal/measurable residual disease; MTD, maximum-tolerated dosage; OS, overall survival; Ph, Philadelphia chromosome; RR, relapsed/refractory.

with RR diffuse large B-cell lymphoma, based on findings from the pivotal JULIET study. ${ }^{40}$ Although immunotherapies in development are discussed in a separate section of this manuscript, it's important to acknowledge that with 84 active immunotherapy clinical trials for ALL registered with the US National Library of Medicine in June 2020, additional options will emerge every year.

\section{Blinatumomab}

Blinatumomab is a BiTE antibody construct that directs CD3 positive $\mathrm{T}$ cells to CD19-positive cells. CD19 is expressed on blast cells in $>95 \%$ of cases of B-cell precursor ALL. Results from the landmark trials leading to blinatumomab's approval are described in table 4.

Data from the phase III randomized clinical trial, TOWER, demonstrated that blinatumomab increased median OS compared with chemotherapy in patients with heavily pretreated Philadelphia chromosome negative $(\mathrm{Ph}-)$ B-ALL. ${ }^{20}$ The median OS was 7.7 months in the blinatumomab group and 4.0 months in the chemotherapy group $(\mathrm{p}=0.01)$. Remission rates within 12 weeks after initiation of treatment were significantly higher in the blinatumomab group than in the chemotherapy group, both with respect to CR with full hematological recovery ( $34 \%$ vs $16 \%$; $\mathrm{p}<0.001)$ and with respect to CR with full, partial, or incomplete hematological recovery ( $44 \%$ vs $25 \%$; $\mathrm{p}<0.001)$. Treatment with blinatumomab resulted in a higher rate of event-free survival (EFS) than that with chemotherapy (6-month estimates, $31 \%$ vs $12 \%$; HR for an event of relapse after achieving a CR with full, partial, or incomplete hematological recovery, or death, $0.55 ; 95 \%$ CI, 0.43 to $0.71 ; \mathrm{p}<0.001)$, as well as a longer median remission duration (7.3 vs 4.6 months).
Based on data from these trials, the FDA granted full approval to blinatumomab in July 2017 for patients with RR B-ALL. ${ }^{31}$ Blinatumomab efficacy has also been evaluated as a therapy for patients with B-ALL who are in morphological remission after induction chemotherapy, but are positive for MRD. One hundred and sixteen patients received blinatumomab. Eighty-eight (78\%) of 113 evaluable patients achieved a complete MRD response. In the subgroup of 110 patients with $\mathrm{Ph}-\mathrm{ALL}$ in hematological remission, the relapsefree survival (RFS) at 18 months was $54 \%$. Median OS was 36.5 months. In landmark analyses, complete MRD responders had longer median RFS (23.6 vs 5.7 months; $\mathrm{p}=0.002)$ and OS (38.9 vs 12.5 months; $\mathrm{p}=0.002$ ) compared with MRD non-responders. ${ }^{32}{ }^{41}$ On March 29, 2018, the FDA approved blinatumomab for patients with B-ALL with positive MRD. ${ }^{31}$

\section{Inotuzumab ozogamicin}

Inotuzumab ozogamicin is a humanized anti-CD22 monoclonal antibody conjugated to calicheamicin, a cytotoxic antibiotic agent. After the conjugate binds to CD22, the CD22-conjugate complex is rapidly internalized, and calicheamicin is released. Calicheamicin binds to the minor groove of DNA and induces doublestrand breaks and subsequent apoptosis (table 3). ${ }^{42}$ The FDA approved inotuzumab ozogamicin on August 17, 2017 for the treatment of patients with RR B-ALL. ${ }^{43}$ In the phase III INO-VATE trial, 109 patients with RR B-ALL, regardless of Philadelphia chromosome status, received inotuzumab ozogamicin. CR was achieved in $80.7 \%$ of patients who were treated with inotuzumab ozogamicin (95\% CI, $72.1 \%$ to $87.7 \%$ ) compared with $29.4 \%$ of patients $(\mathrm{n}=109)$ who were treated with standard-of-care (SOC) chemotherapy 
(95\% CI, $21.0 \%$ to $38.8 \%$; $<<0.001$ ). Median OS for inotuzumab ozogamicin was 7.7 months $(95 \% \mathrm{CI}, 6.0 \%$ to $9.2 \%$ ) versus 6.7 (95\% CI, $4.9 \%$ to $8.3 \%)$ months for standard care; the 2-year OS rates were $23 \%(95 \%$ CI, $16 \%$ to $30 \%)$ versus $10 \%(95 \%$ CI, $5 \%$ to $16 \%)$, respectively. The primary objective to demonstrate significantly improved final OS with inotuzumab ozogamicin compared with standard care was not met. An exploratory post hoc restricted mean survival time analysis was applied to more precisely define the clinical benefit of inotuzumab ozogamicin. In this analysis, mean overall survival was longer in the inotuzumab ozogamicin group than in the standard-therapy group (mean $[ \pm \mathrm{SE}], 13.9 \pm 1.10$ months versus $9.9 \pm 0.85$ months; $\mathrm{p}=0.005) .{ }^{21}$

\section{Tisagenlecleucel}

Tisagenlecleucel is an anti-CD19 CAR T cell therapy, generated via the ex vivo genetic engineering and expansion of $\mathrm{T}$ lymphocytes obtained from the patient's blood to incorporate a novel receptor into the $\mathrm{T}$ cell repertoire. Engineered $\mathrm{T}$ cells recognize and associate with antigen-positive malignant cells for elimination. In the phase I/IIa ELIANA trial, 75 children and young adults (median age: 11 years, range: 3 to 23 years) with RR B-ALL were treated with tisagenlecleucel. Of the enrolled patients, $46(61 \%)$ had undergone prior allo-HCT. Before tisagenlecleucel infusion, 72 of 75 patients $(96 \%)$ received lymphodepleting chemotherapy. The overall remission rate was $81 \%$ (95\% CI, $71 \%$ to $89 \%)$; 45 patients $(60 \%)$ had CR, and $16(21 \%)$ had CR with incomplete hematologic recovery (CRi). All patients who had a best overall response of CR with or without complete hematologic recovery were negative for minimal residual disease; $95 \%$ (58 of 61 ) of these patients were negative by day 28. The median duration of follow-up among patients who received a tisagenlecleucel infusion was 13.1 months. The rates of EFS and OS were $73 \%(95 \%$ CI, $60 \%$ to $82 \%$ ) and $90 \%$ (95\% CI, $81 \%$ to $95 \%$ ), respectively, at 6 months and $50 \%$ (95\% CI, $35 \%$ to $64 \%)$ and $76 \%(95 \%$ CI, $63 \%$ to $86 \%)$ at 12 months. ${ }^{33}$

On August 30, 2017, tisagenlecleucel became the first ever FDA-approved CAR $\mathrm{T}$ therapy, gaining approval for the treatment of patients $\leq 25$ years of age with B-ALL who have relapsed or have not responded after two previous lines of therapy. ${ }^{44}$ Approval was based on data from 63 patients, and among the infused patients, $52(83 \%)$ achieved CR/CRi, all of which were MRD negative. Recently presented data suggest that responses to anti-CD19 CAR $\mathrm{T}$ therapy are exceptionally durable. Follow-up analyses from 97 patients enrolled in the ELIANA trial demonstrate 18-month RFS of $66 \%$ (95\% CI, $52 \%$ to $77 \%$ ) and 18 -month OS probability of $70 \%$ (95\% CI, $58 \%$ to $79 \%$ ) with median OS not yet reached at the time of analysis. ${ }^{45}$

It is of note that the current FDA approval for tisagenlecleucel does not include adult patients with ALL aged 26 years or older. ${ }^{46}$ As such, clinical trials investigating antiCD19 CAR T cell therapy for the treatment of older adult patients with ALL are underway. Approval for this treatment modality for adult patients with ALL is anticipated in the near future.

\section{MRD status}

Measurable residual disease (MRD) has been used to identify CR patients at a high risk of relapse. MRD is defined as the post-therapy persistence of leukemic cells at levels below morphological detection in the bone marrow or peripheral blood. MRD status of patients is considered a risk factor for relapse and is often used to select the next appropriate strategy for previously treated patients with acute leukemia. Blinatumomab is the only FDA approved immunotherapy in the ALL MRD positive disease setting at the time of guideline preparation. ${ }^{31}$

The role of MRD in treatment decisions for ALL remains an active area of investigation. Outcomes are generally poor for patients with detectable MRD at the time of allo-HCT. ${ }^{34} 47$ However, the prognostic utility of MRD may vary depending on the assay used for measurement. MRD may be assessed by several methods including multicolor flow cytometry (MFC), PCR, and next-generation sequencing (NGS). Although flow cytometry is typically considered the gold standard, molecular methods that identify leukemic cells with high sensitivity are also used in ALL. ${ }^{48}$ Studies are ongoing to determine whether detection of leukemic DNA above a certain threshold may consistently predict relapse after therapy. Newer sequencing methods may offer more robust predictive power. NGS-MRD predicted relapse and survival more accurately than MFC-MRD $(\mathrm{p}<0.0001)$, especially in the MRD-negative patients (relapse, $0 \%$ vs $16 \%$; $\mathrm{p}=0.02$; 2-year OS, $96 \%$ vs $77 \%$; $\mathrm{p}=0.003$ ). Post-HCT NGS-MRD detection was better at predicting relapse than MFC-MRD $(p<0.0001)$, especially early after HCT (day 30 MFC-MRD positive relapse rate, 35\%; NGSMRD positive relapse rate, $67 \% ; \mathrm{p}=0.004) .{ }^{49}$ Ongoing studies are evaluating how best to incorporate NGSbased testing into patient care, especially in relation to allo-HCT.

Results of a large meta-analysis of 13,637 patients with ALL treated mainly with chemotherapy indicate that increased EFS significantly correlates with the presence of MRDnegative disease after treatment in both children and adults (pediatric: HR=0.23; 95\% Bayesian CI (BCI): 0.18 to 0.28; adult: $\mathrm{HR}=0.28$; $95 \%$ BCI, 0.24 to 0.33$).{ }^{36}$ Adults who were MRD-negative had EFS of approximately $64 \%$ at 10 years versus only $21 \%$ for those who were MRD-positive. The relative benefit in EFS of having achieved MRD negativity was comparable in both age groups.

Among patients receiving CAR $\mathrm{T}$ therapy, a subset who achieve MRD-negative status experience durable remissions that persist with no further treatment. ${ }^{50}$ Although the factors that favor durable remission after achieving 
MRD-negative status are under investigation, in one study with patients treated with CAR T cells, the EFS and OS were significantly better in the patients who achieved MRDnegative CR compared with those who did not (median EFS 7.6 vs 0.8 months; $\mathrm{p}<0.0001$; median OS 20.0 vs 5.0 months; $\mathrm{p}=0.014)$. Patients achieving MRD-negative CR showed that lower prelymphodepletion LDH concentration, higher prelymphodepletion platelet count, incorporation of fludarabine into the lymphodepletion regimen, and allo-HCT after CAR T cell therapy were associated with better EFS. ${ }^{50}$

\section{Combination of allogeneic cell transplantation with immunotherapy}

Guidelines concerning indications for allo-HCT have been generated by other societies and are outside the scope of this manuscript. ${ }^{26} 52$ However, it is important to address the role of allo-HCT and current immunotherapies, especially as more agents receive FDA approvals. Several publications have discussed the application of immunotherapy both before and after allo-HCT. Relapse after HCT is associated with a very poor prognosis, yet immunotherapies may improve outcomes. Although further trials are needed, donor-derived CD19-targeted $\mathrm{T}$ cell infusions have been evaluated for relapsed B-ALL after haplo-HCT. ${ }^{53}$ Additionally, trials assessing tisagenlecleucel (ELIANA) and blinatumomab (TOWER) included patients with B-ALL who had relapsed following prior allo-HCT. Both agents were effective and, importantly, tisagenlecleucel treatment did not result in new episodes of graft-versus-host disease (GVHD). ${ }^{20} 33$ Inotuzumab ozogamicin and blinatumomab are both under investigation as salvage regimens after HCT. Importantly, inotuzumab ozogamicin carries a black-box warning for hepatotoxicity, including fatal and life-threatening sinusoidal obstruction syndrome (SOS)/veno-occlusive disease (VOD) in patients undergoing HCT after treatment. ${ }^{54}$

Allo-HCT after CAR T cell treatment has also been evaluated in clinical trials as a consolidation therapy to prevent relapse. In the ELIANA trial, eight patients while in reemission received allo-HCT after tisagenlecleucel. ${ }^{45}$

In a separate trial, among 44 patients who had a CR after the infusion of CAR T cells, 26 (59\%) were observed who had no further therapy and 17 patients (39\%) proceeded to transplantation. The median time from the CAR $\mathrm{T}$ cell infusion to transplantation was 74 days (range, 44 to 312 ). Of the 17 patients who underwent allo-HCT after the CAR T cell infusion, 5 patients were alive and had CRs, 6 had relapses, and 6 died from transplant-related toxic effects. Among the 32 patients who had a MRD-negative CRs, there was no significant difference in EFS and OS between patients who underwent transplantation and those who did not ( $\mathrm{p}=0.64$ for EFS and $\mathrm{p}=0.89$ for OS by the log-rank test)..$^{5}$

Concerns have been raised about the use of checkpoint inhibitors prior to or after allo-HCT. While checkpoint inhibition may augment the graft-versus-tumor effect, immune activation may place patients at risk of GVHD. ${ }^{56}{ }^{57}$ The timing of administration may also play a role in determining the safety of checkpoint inhibition in a treatment plan that includes transplant. A review of 24 studies encompassing 283 patients with a variety of hematological malignancies including 28 patients with AML and 4 patients with ALL found that the incidence of acute GVHD among patients receiving checkpoint inhibitor therapy prior to allo-HCT was $56 \%$, and $29 \%$ of patients developed chronic GVHD. There was a trend toward higher incidences of GVHD in patients with shorter median intervals between receiving the last dose of checkpoint inhibitor therapy and allo-HCT compared with patients having longer intervals. ${ }^{57}$ The duration during which GVHD risk may be increased by persistent immune activation induced by checkpoint inhibition in patients with leukemia is not currently known.

\section{Panel recommendations}

- While a number of immunotherapies do have a role in the treatment of patients with acute leukemia in various settings, clinical trial enrollment should be considered at each juncture.

- New, experimental drugs should be administered at centers that have proper support, infrastructure, and subspecialties.

- Patients with relapsed B-ALL should receive immunotherapy as a bridging therapy to induce remission prior to allo-HCT.

- Options for patients with relapsed ALL after one line of prior therapy include clinical trial enrollment, treatment with blinatumomab or inotuzumab ozogamicin, or allo-HCT.

- For patients with relapsed B-ALL and a high disease burden, inotuzumab ozogamicin should be considered first followed by blinatumomab for persistent disease or MRD positivity, based on the clinical experience and consensus of the Expert Panel.

- Because inotuzumab ozogamicin increases the risk of SOS/VOD in subsequent transplants, the number of cycles should be limited if allo-HCT is planned.

- Patients with newly diagnosed B-ALL who are MRD positive after undergoing induction chemotherapy should be offered blinatumomab.

- CAR T cell therapy is strongly recommended for patients with relapsed ALL after second-line and/or third-line therapy.

- Outcomes for MRD-positive patients are generally poor; therefore, enrollment into a clinical trial should be considered to help achieve an MRD-negative status.

\section{IMMUNOTHERAPY FOR THE TREATMENT OF PATIENTS WITH AML}

To date, relatively few immunotherapy approaches have been approved for the treatment of patients with AML compared with those available for the treatment of patients with ALL, although many are in clinical trials and some show promising preliminary results. One possible cause for this discrepancy is the difficulty in identifying targetable antigens on myeloid cells that allow for safe anticancer activity with defined long-term effects on the patient. Currently, the only approved immunotherapeutic 
strategies for treating AML are allo-HCT and the CD33targeting ADC GO. However, several research programs and clinical trials are currently underway hoping to further the repertoire of therapies such as checkpoint inhibitors, unconjugated antibodies, BiTEs, and CAR T cell therapies in the treatment of AML.

\section{Approved agents and indications \\ Gemtuzumab ozogamicin}

GO, an anti-CD33 ADC, using a calicheamicin-derivative cytotoxic drug, was the first ADC approved for human use by the FDA for AML. On binding to CD33, GO is rapidly internalized, leading to the intracellular release of calicheamicin, a potent DNA-damaging agent that causes single-strand and double-strand breaks, which leads to checkpoint activation, cell cycle arrest, and the activation of cell death pathways. ${ }^{58}$ GO was granted accelerated approval in the USA in 2000 for patients aged 60 years or older with CD33-positive AML in first relapse and who are not considered to be candidates for cytotoxic chemotherapy. Accelerated approval was granted after promising results from a single phase I study and three phase II trials, where the overall response rate (ORR) was $30 \%$ in a total of 142 patients. ${ }^{59}$ After the initial approval, however, GO was increasingly recognized to be associated with hepatotoxicity and severe $\mathrm{SOS},{ }^{60}$ leading the FDA to issue a black-box warning. The drug was voluntarily withdrawn in 2010 after a postapproval phase III clinical trial that found an increase in treatment-related mortality with no improvement in CR rate, disease-free survival, or overall survival (OS), with the addition of GO to standard induction or postconsolidation therapies. ${ }^{61}$

However, recently, GO has reemerged as an option for the treatment of AML. In 2017, GO was reapproved for the treatment of newly diagnosed CD33-positive AML in adults (both alone or in combination with induction chemotherapy) and as a single agent for the treatment of RR CD33-positive AML in adults and in pediatric patients aged 2 years and older. ${ }^{30}$ The studies leading to reapproval are summarized in table 5. Additionally, a 2014 meta-analysis of five trials encompassing 3325 patients found that the addition of GO to induction chemotherapy significantly reduced the risk of relapse (OR $0.81 ; \mathrm{p}=0.0001$ ) and improved OS at 5 years (OR 0.90; $\mathrm{p}=0.01){ }^{62}$

The current FDA approval indicates GO as both a single agent and in combination with chemotherapy during induction and consolidation for newly diagnosed AML in adults and in pediatric patients aged 1 month and older. In the RR setting, GO is approved for adult patients and is used as a monotherapy.

\section{MRD status}

The importance of the MRD status of patients has also been investigated in AML settings. Several strategies exist to assess MRD status, including MFC, qRT PCR, and NGS. ${ }^{25}$ In one study of 482 patients aged 18 to 65 years with newly diagnosed AML, molecular MRD status determined via NGS correlated with risk of relapse in patients who achieved CR after induction therapy. ${ }^{35}$ The detection of molecular MRD was associated with a significantly higher relapse rate than no detection $(55.4 \%$ vs. $31.9 \%$; HR, 2.14; $\mathrm{p}<0.001)$, as well as with lower rates of RFS (36.6\% vs. $58.1 \%$; HR for relapse or death, 1.92; $\mathrm{p}<0.001$ ) and OS $(41.9 \%$ vs. $66.1 \%$; HR for death, 2.06; $\mathrm{p}<0.001)$. In a meta-analysis, pretransplant MRD was associated with worse leukemia-free survival $(\mathrm{HR}=2.76 ; 95 \% \mathrm{CI}, 1.90$ to $4.00)$, (OS HR $=2.36$; $95 \%$ CI, 1.73 to 3.22 ), and cumulative incidence of relapse ( $\mathrm{HR}=3.65 ; 95 \%$ CI, 2.53 to 5.27 ), but not non-relapse mortality (HR $=1.12 ; 95 \%$ CI $(0.81$

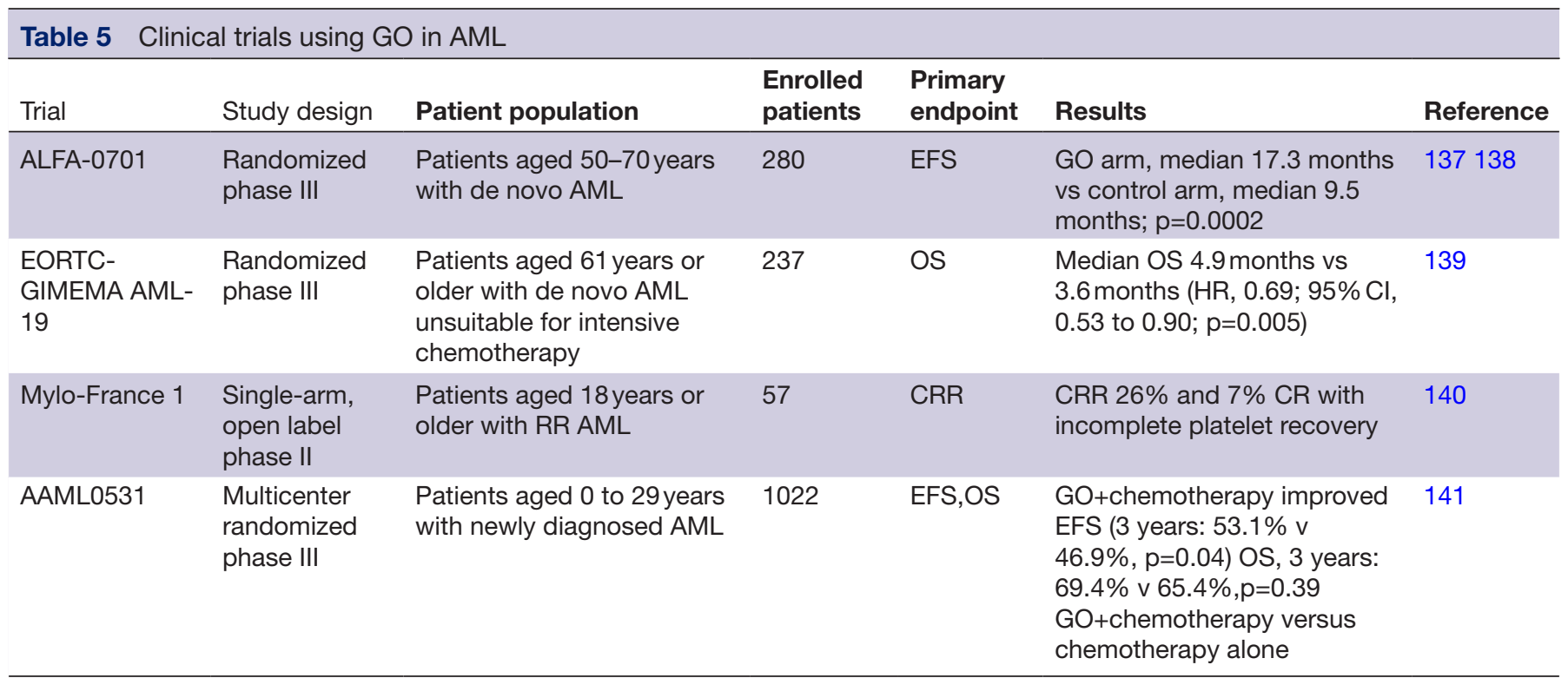

AML, acute myeloid leukemia; CR, complete response; CRR, complete response rate; EFS, event-free survival; GO, Gemtuzumab ozogamicin; OS, overall survival; RR, relapsed/refractory. 
to 1.55$)$. These associations held regardless of detection method, conditioning intensity, and patient age. ${ }^{63}$

Combination of allogeneic cell transplantation with immunotherapy Immunotherapies for the treatment of AML remain an ongoing subject of research, and data on the optimal integration of these novel agents into established approaches are limited. Given that graft-versus-leukemia effects are an important contributor to outcomes after allo-HCT, ${ }^{10-12}$ caution is warranted when incorporating any immunetargeting modality into a treatment plan that includes transplant. One phase I/Ib clinical trial assessing the anticytotoxic T-lymphocyte-associated protein 4 (CTLA-4) checkpoint inhibitor ipilimumab after allo-HCT in patients with relapsed hematological malignanciesincluding 12 patients with AML-observed 1 year OS of $49 \%$ with $14 \%$ of total patients (4/28) developing GVHD. ${ }^{56}$ Another phase I study demonstrated that pediatric patients with AML who received reduced-intensity conditioning allo-HCT followed by consolidation therapy involving GO had a probability of developing grades II to IV acute and chronic GVHD of $21 \%$ and $33.5 \%$, respectively. Probability of OS after allo-HCT and GO consolidation at 1 and 5 years was $78 \%$ and $61 \%$, respectively. Probability of 5-year EFS after allo-HCT and GO consolidation in patients in CR1 was 78\%. ${ }^{64}$

Although FDA-approved immunotherapies have demonstrated enhanced curative potential compared with standard treatment modalities, several patients will not respond or will relapse after immunotherapy-induced remissions. The pathophysiology of AML postrelapse remains an ongoing and important area of study. Deregulation of pathways involved in T cell-mediated allorecognition has been identified as a feature and driver of AML relapses after allo-HCT, ${ }^{65}$ including downregulation of major histocompatibility complex class II genes involved in antigen presentation, loss of HLA class I antigens in the case of HLA-matched and HLA-mismatched transplants, and the acquisition of de novo mutations. ${ }^{66-68}$ These changes potentially offer insights that could eventually be translated into personalized therapies.

Relapse after allo-HCT in AML is generally associated with a very poor prognosis without active treatment. Remission may be achieved through the administration of donor lymphocyte infusion (DLI). A retrospective, analysis of 399 patients with AML in first hematological relapse after allo-HCT estimated that DLI prolonged survival rates at 2 years to $21 \% \pm 3 \%$ compared with $9 \% \pm 2 \%$ for patients not receiving DLI. ${ }^{69}$ The use of DNA methyltransferase inhibitors (DNMTs; azacitidine, Aza; or decitabine, DAC) have been used in conjunction with DLI to induce antileukemia CD8+ T cell responses by enhancing the expression of epigenetically silenced tumor antigens. The prospective multicenter AZARELA trial reported encouraging ORRs for Aza+DLI treatment after relapse, including five patients continuing CR for a median of 777 days without any additional treatment. The incidence of acute and chronic GVHD was $37 \%$ and $17 \%$, respectively, and all cases were mild. ${ }^{70}$ Several other studies have demonstrated similar benefits with DNMTs, with or without DLI, for relapsed patients after allo-HCT. ${ }^{69}{ }^{71-73}$ It is currently not known whether DLI combined with DNMTs is more effective than either therapy alone. Ongoing studies are evaluating strategies to enhance response rates for DLI post-transplant, including in combination with immunomodulatory agents.

\section{Panel recommendations}

- While many immunotherapy approaches may have a role in the treatment of patients with AML in various settings, clinical trial enrollment should be considered at each juncture.

- GO may be added in favorable and possibly intermediate-risk patients with AML during induction chemotherapy.

- GO should be considered at the time of AML relapse and in newly diagnosed patients with AML who are not eligible to receive intensive induction chemotherapy.

- Outcomes are generally worse after allo-HCT for patients who achieve morphological remission after induction chemotherapy, yet display persistent MRD. Further studies are needed to identify therapeutic options for these patients. Therefore, enrollment into a clinical trial should be considered to help achieve an MRD-negative status.

\section{EMERGING IMMUNOTHERAPIES FOR THE TREATMENT OF PATIENTS WITH ACUTE LEUKEMIA}

A number of novel agents and strategies are being tested in preclinical and clinical settings. Promising results have been reported for both antibody-based and cell-based therapies, especially in the rapidly burgeoning CAR T cell field. As novel immunotherapies demonstrate safety and efficacy in clinical trials, more options will emerge for practicing clinicians. Because many of these agents have not yet been approved by the FDA, the committee emphasizes that new experimental drugs should only be administered at centers with proper support, infrastructure, and subspecialties in place to monitor outcomes and adverse events (AEs).

\section{Agents and indications \\ Rituximab}

Rituximab, a chimeric anti-CD20 antibody, has been evaluated with combination chemotherapy for patients with B-ALL demonstrating improved EFS as well as OS benefit and molecular CR rates (table 6) ${ }^{1574}$ Although rituximab is not FDA approved for the treatment of CD20+ ALL, rituximab is being used in combination with ALL chemotherapeutic regimens during induction, consolidation, and maintenance therapies.

\section{Bispecific cell engager therapies}

Based on the success of blinatumomab in ALL, efforts are underway to develop similar agents targeting antigens specific for AML, such as CD123 and CD33. ${ }^{75}$ Additional studies for bispecific cell engagers targeting the leukemic cell antigen CD33 are ongoing. A phase I study 


\begin{tabular}{|c|c|c|c|c|c|c|}
\hline Trial & Study design & $\begin{array}{l}\text { Patient } \\
\text { population }\end{array}$ & $\begin{array}{l}\text { Enrolled } \\
\text { patients }\end{array}$ & Endpoints & Results & Reference \\
\hline GRAAL & $\begin{array}{l}\text { Randomized } \\
\text { phase III }\end{array}$ & $\begin{array}{l}\text { Adults with } \\
\text { CD20+, Ph- } \\
\text { B-ALL }\end{array}$ & 209 & EFS & $\begin{array}{l}65 \% \text { with rituximab }(95 \% \mathrm{Cl}, 56 \% \text { to } \\
75 \%) \text { versus } 52 \% \text { with standard of } \\
\text { care }(95 \% \mathrm{Cl}, 43 \% \text { to } 63 \%) ; \mathrm{HR}=0.66 \text {; } \\
(95 \% \mathrm{Cl}, 0.45 \text { to } 0.98 ; \mathrm{p}=0.04)\end{array}$ & 15 \\
\hline $\begin{array}{l}\text { Thomas et al, } \\
\text { JCO } 2010\end{array}$ & $\begin{array}{l}\text { Prospective, } \\
\text { non-randomized }\end{array}$ & $\begin{array}{l}\text { Adolescents } \\
\text { and adults } \\
\text { with de novo } \\
\text { Ph- B-ALL }\end{array}$ & 282 & $\begin{array}{l}\text { CR rate; } \\
\text { 3-year CRD } \\
\text { rate; OS } \\
\text { rate }\end{array}$ & $\begin{array}{l}\text { In the younger (age }<60 \text { years) CD20- } \\
\text { positive subset, rates of CRD and OS } \\
\text { were superior with the modified hyper- } \\
\text { CVAD and rituximab regimens compared } \\
\text { with standard hyper-CVAD (70\% v 38\%; } \\
\text { p<.001\% and } 75 \% \text { v } 47 \%, p=.003) \text {. } \\
\text { Older patients with CD20-positive ALL } \\
\text { did not benefit from rituximab-based } \\
\text { chemoimmunotherapy }\end{array}$ & 74 \\
\hline
\end{tabular}

ALL, acute lymphoblastic leukemia; B-ALL, B-cell acute lymphoblastic leukemia; CR, complete response; CRD, CR duration; CVAD, fractionated cyclophosphamide, vincristine, doxorubicin, dexamethasone; EFS, event-free survival; OS, overall survival; Ph, Philadelphia chromosome.

of the CD33/CD3 BiTE AMG330 demonstrated acceptable safety profiles in 35 patients with RR AML. ${ }^{76}$ Studies are also ongoing for another CD33/CD3 bispecific cell engager, AMV564, which demonstrated safety and antileukemia activity in a first-in-human trial in patients with RR AML. ${ }^{77}$

A study evaluating a trispecific killer engager (TriKE) therapy engaging CD16 on natural killer (NK) cells and targeting CD33 on AML/MDS with an interleukin (IL)-15 linker between the two domains has just been opened for accrual in AML (NCT03214666). The drug differs from bispecific cell engagers due to the NK cell activation it provides while bringing them in proximity to malignant blasts due to the presence of the IL-15 linker domain. At the time of publication, the single-center phase I/II clinical trial is enrolling patients with refractory AML defined as failure to achieve remission after at least three induction attempts or relapsed AML who are not a candidate for HCT after at least one re-induction attempt, as well as patients with prior HCT relapse beyond 3 months without active GVHD.

\section{Antibody-drug conjugates}

Based on extremely promising preclinical data, several ADCs targeting different surface markers and carrying different payloads have begun making their way through clinical trials. Initial results from the ongoing SIERRA study (NCT02665065) have indicated safety and feasibility for Iomab-B, an anti-CD45 ADC-carrying radioactive ${ }^{131} \mathrm{I}$, as a bridging therapy before transplant for patients with RR AML. Analysis of the first $25 \%$ of enrolled patients $(n=38)$ showed a rapid reduction in the leukemia burden after Iomab-B treatment, setting the stage for successful engraftment after allo-HCT. ${ }^{78}$ Another ADC, IMGN632, a CD123-targeting antibody linked to a novel DNAalkylating agent, has demonstrated in an ongoing phase I study objective responses in RR AML, including 1 CR and $3 \mathrm{CRi}$, with no dose-limiting toxicities. ${ }^{79}$ Additionally, the CD30-specific ADC brentuximab vedotin has demonstrated favorable safety in a phase I trial (NCT01830777) when administered in combination with a conventional mitoxantrone, etoposide, and cytarabine reinduction chemotherapy regimen for patients with CD30+ RRAML. ${ }^{80}$

\section{Checkpoint inhibitors}

To date, immune checkpoint inhibitors, which have demonstrated efficacy for treating patients with solid tumors and classical Hodgkin lymphoma, have not had similar significant success in acute leukemias. Ongoing studies are evaluating the combination of checkpoint inhibition with blinatumomab for B-ALL, and one phase I study reported an MRD-negative CR rate of $80 \%$ in five heavily pretreated patients with a significant baseline disease burden. ${ }^{81}$ Checkpoint inhibitors remain under investigation as single agents for maintenance following allo-HCT, especially in the context of AML, where some studies indicate that checkpoint inhibition augments the graft-versus-leukemia effect as well as in combination regimens with chemotherapy. Combinations of nivolumab (an anti-PD-1 antibody), in combination with hypomethylating agents (HMAs) or induction chemotherapy have recently been reported. ${ }^{82-84}$ In one example, patients with RR AML received nivolumab with azacitidine. The overall response rate (ORR) was $33 \%$ including 15 (22\%) CR/CRi, 1 partial response (PR), and 7 patients with hematological improvement maintained for 6 months or longer. The ORR was $58 \%$ and $22 \%$, in HMA-naive $(n=25)$ and HMA pretreated $(n=45)$ patients, respectively. ${ }^{82}$ In another example, patients with RR AML received pembrolizumab following high-dose cytarabine. The ORR of 10 evaluable patients was $50 \%$, with $4 \mathrm{CR} /$ $\mathrm{CRi}^{85}$ Other promising results emerged from a phase II trial evaluating a triplet regimen combining nivolumab 
with ipilimumab and azacitidine, with a CR/CRi rate of $36 \%$ and a 1-year survival rate of $45 \%$ in a cohort of 31 patients with RR AML. ${ }^{86}$ These, and several other studies, are currently ongoing.

\section{CAR T cell therapies}

Bolstered by the success of CD19 targeting CAR T cell therapies in the pediatric B-ALL setting, ongoing research is evaluating novel agents for patients with ALL, new approaches that can provide adult patients with ALL access to CAR T cell treatment, and strategies for the treatment of patients with AML. Several studies are working to develop CAR T cell therapies targeting nonCD19 antigens for patients with CD19-negative disease or for those who relapse after anti-CD19 CAR T cell infusion. Among the most mature are CD22-directed CAR T cells for the treatment of RR B-ALL. Fry and colleagues reported initial results from a phase I trial testing a new CD22-targeted CAR in 21 children and adults, including 17 who were previously treated with CD19-directed immunotherapy. Dose-dependent antileukemic activity was observed, with CR obtained in $73 \%(11 / 15)$ of patients receiving $\geq 1 \times 10^{6}$ CD22-CAR $\mathrm{T}$ cells per kilogram body weight, including in five out of five patients with CD19dim or CD19-negative B-ALL. Median remission duration was 6 months. Relapses were associated with diminished CD22 site density that likely permitted CD22+ cell escape from killing by CD22-CAR T cells. ${ }^{28} \mathrm{~A}$ follow-up report on that trial included 52 patients. 36 patients $(69.2 \%)$ had undergone HCT; 30 (57.7\%) had prior CD19 CAR; 22 (42.3\%) had prior blinatumomab; and $28(53.8 \%)$ subjects had a CD19-negative population, including 2 who were inherently partial CD19 -negative without prior targeted therapy. The CR rate was $72.5 \%$ overall; $84 \%$ at the current dose level. This included CRs seen in subjects who were non-responders to CD19 CAR T cell therapy and/or blinatumomab. The longest remission was $>3$ years $(n=1)$ post-CAR $\mathrm{T}$ cell infusion. Relapse occurred at a median of 6 months postinfusion in $23(64 \%)$ subjects primarily due to CD22 modulation. Twelve patients proceeded to HCT following CD22 CAR T cell therapy. ${ }^{87}$ Another study in 34 pediatric and adult patients with RR B-ALL who did not respond from previous CD19 CAR T cell therapy were treated with CD22 CAR T cell therapy found that CR or CRi was achieved in 24 of 30 patients (80\%) that could be evaluated on day 30 after infusion, which accounted for $70.5 \%$ of all 34 enrolled patients. ${ }^{88}$

CAR $\mathrm{T}$ cell therapies for the treatment of patients with AML are also in development. One promising strategy currently being assessed in multiple clinical trials involves CAR T cell therapies that target CD33 on myeloid cells. Anti-CD123 CAR T cell therapies for the treatment of patients with RR AML are also being evaluated. ${ }^{89}$ Other clinical trials are ongoing, including CAR T cells targeted against CD7 (NCT04033302) and FLT3 (NCT03904069).

\section{Other cell therapies}

Beyond CAR T cells, several other immune effector cell-based therapies are undergoing evaluation. One approach involves the infusion of donor lymphocytes genetically engineered to express the herpes simplex virus thymidine kinase (the so-called "suicide gene") after haploidentical HCT. ${ }^{90}$ Other studies are evaluating additional strategies, including infusion of $\mathrm{T}$ regulatory type 1 cells after HCT as well as personalized NK cell therapy after chemotherapy, and umbilical cord blood transplant.

Advances have been made in cytokine-induced NK cell therapy as well as in the infusion of autologous $\mathrm{T}$ cells specific for WT1 for AML. A first-in-human phase I clinical trial demonstrated that adoptively transferred allogeneic NK cells induced to a memory-like phenotype through preincubation with IL-12, IL-15, and IL-18 proliferated and expanded in patients with AML and demonstrated robust responses against leukemia targets. ${ }^{91}$ Donorderived WT1-specific CD8+ cytotoxic T cells have demonstrated direct evidence of antileukemic activity ${ }^{92}$ and prophylactic infusion of Epstein-Barr virus-specific donor $\mathrm{CD} 8+\mathrm{T}$ cells transduced with a $\mathrm{T}$ cell receptor specific for WT1 post-HCT was associated with $100 \%$ RFS in 12 patients with a median follow-up of 44 months, while a concurrent comparative group of 88 patients with similar risk AML had 54\% RFS ( $\mathrm{p}=0.002){ }^{93}$

As personalized cell therapy requires several weeks of production, there is a growing interest in off-the-shelf NK cell products. One way to accomplish this goal is by differentiation of induced pluripotent stem cells (iPSC) into an unlimited supply of cryopreserved NK cells for immediate availability and allowing for multidose strategies. ${ }^{94}$ One example of this strategy, FT516, which consists of iPSC-derived NK cells engineered with a high-affinity, non-cleavable CD16 Fc receptor, has entered phase I/Ib clinical trials in patients with primary refractory AML and relapsed AML (NCT04023071).

\section{Panel recommendations}

- Patients should be treated with FDA-approved therapies, if available, with clinical trial enrollment considered at each juncture.

- New, experimental drugs should be administered at prepared institutions. Institutions need to have proper support, infrastructure, and subspecialties.

- The use of rituximab in patients with CD20+ B-ALL is recommended.

\section{ROLE OF IMMUNOTHERAPY POST-CAR T CELL THERAPY}

CAR T cell therapies have offered significant survival benefits for patients with ALL and data suggest that responses are durable. In some cases, however, CAR T cell therapy is ineffective due to either lack of the targetable antigen or antigen loss after initial therapy. Therefore, many novel CAR $T$ cell therapies are under investigation to provide secondary options for these patients. In some cases, other immunotherapeutics may be options for patients who 
have relapsed or are refractory to FDA-approved CAR T cell therapies.

Although trials are underway for tisangenlecleucel as treatment for pediatric and young adult patients with B-ALL who received first-line treatment and are MRD positive at the end of consolidation therapy (CASSIOPEIA, NCT03876769), the current FDA approval is for refractory patients or in patients in second relapse or later. Relapse after CAR T cell therapy is sometimes due to the loss of the target antigen. ${ }^{28} 45$ The prognosis of patients who relapse post-CAR $\mathrm{T}$ cell administration is often considered poor, especially considering that the anti-CD19 blinatumomab is also rendered ineffective in patients with CD19 loss.

The availability of multiple CD19-targeting therapies including BiTEs and CAR T cells makes decisions on optimal treatment sequencing challenging, especially given the possibility for relapse mediated by antigen loss. ${ }^{95}$

Options for patients who relapse post-CAR T cell therapy include salvage chemotherapy, clinical trial enrollment, allo-HCT, or retreatment with CAR T cells (potentially targeting different antigens, depending on the mechanism of relapse). Allo-HCT transplant is potentially an option for patients who relapse after CAR T cell therapy, but these patients are often ineligible for transplant.

There are multiple studies investigating CAR $\mathrm{T}$ cell therapies that target antigens other than CD19 for the treatment of patients with CD19-negative ALL. There have been encouraging reports of therapeutic response in patients who have relapsed after CD19-targeted CAR T-cell therapy. For example, one study notes that patients with CD19-negative B-ALL displayed a median remission duration of 6 months after receiving anti-CD22 CAR T cell therapy. Of note, relapse due to loss of CD22 was also observed in this trial. ${ }^{28}$ As such, there are clinical studies investigating bispecific CAR T cell therapies that target two antigens concurrently to increase efficacy and reduce the risk of relapse. ${ }^{96}$ In one phase 1 trial of bispecific CD19/ CD22 CAR T cells, CR was achieved in 5/7 (71\%) RR ALL patients by day 21, 4 of which were minimal residual disease negative. Therapy was well tolerated with no dose limiting toxicities. CRS occurred in 5 subjects (Grade 1) with 2 of these subjects experiencing mild neurotoxicity. (Grade 1) ${ }^{97}$ Another study of the CD19/CD22 'cocktail CAR T cell' approach for RR B-ALL demonstrated a 100\% CR/CRi rate on day 20 to 30 after infusion in 15 patients with 14/15 (93.3\%) achieving MRD negativity. ${ }^{98}$ A very low treatment-related toxicity was observed in this trial. Only 1 patient experienced grade 3 CRS and another patient $(6.7 \%)$ developed grade 3 central nervous system toxicity; all other patients were CRS grade $<2$ and CNS grade 0 .

\section{Panel recommendations}

- With very few options available to patients who relapse after CAR T cell therapy, clinical trial enrollment should be strongly considered.
- For patients with ALL who relapse or are refractory to CAR T cell therapy, a consensus could not be reached to recommend one preferred treatment. Potential options could include CAR $\mathrm{T}$ cell therapy targeting different antigens, blinatumomab, or allo-HCT (if eligible).

\section{RECOGNITION AND MANAGEMENT OF IMMUNE-RELATED AES IN PATIENTS WITH ACUTE LEUKEMIA BEING TREATED WITH IMMUNOTHERAPY}

Immune-related AEs are of significant concern in the field of immuno-oncology. Immunotherapies have distinct and significant toxicities requiring skilled management. SITC has published a textbook guide to managing immunotherapy toxicity as well as a consensus statement from the Toxicity Management Working Group concerning the management of toxicities after treatment with checkpoint inhibitors. ${ }^{99}$ Toxicity management after CAR T cell therapy for hematological malignancies is described in a 2018 review publication from SITC. ${ }^{17}$ At the time of publication, two additional SITC clinical practice guidelines for the recognition and management of immunerelated AEs for immune effector cell and checkpoint inhibitor therapies are in preparation. Additionally, the American Society for Transplant and Cellular Therapy has published consensus guidelines for grading CRS and neurological toxicity after CAR T cell therapy. ${ }^{100}$

AEs arising during treatment for ALL with immunotherapy are distinctive and must be recognized early and managed appropriately. Concerning inotuzumab ozogamicin, $46 \%$ of patients treated with inotuzumab ozogamicin in the INO-VATE trial experienced $\geq$ grade 3 AEs, similar to the rate and profile of $\geq$ grade 3 AEs in patients who received SOC chemotherapy $(43 \%)$. VOD occurred more frequently in the inotuzumab ozogamicin group than in the standard-therapy group (in 11\% (15 patients) vs $1 \%$ ( 1 patient)). Of the 48 patients in the inotuzumab ozogamicin group who underwent stem cell transplantation after the trial, 10 had VOD after transplantation. The median time to the development of VOD associated with transplantation in the inotuzumab ozogamicin group was 16 days (range, 3 to 39 days). ${ }^{21}$ Recent consensus recommendations for the prevention and monitoring of VOD associated with inotuzumab ozogamicin include: avoid HCT conditioning regimens containing dual alkylating agents, use prophylactic medicines in patients proceeding to HCT, limit treatment with inotuzumab ozogamicin to 2 cycles, monitor patient weight for fluid retention, and frequently assess liver function. ${ }^{101}$

Both blinatumomab and CAR T cell therapies can result in serious AEs including CRS and neurotoxicities. ${ }^{102} 103$ These two events can be fatal if not properly managed. CRS was the most common AE reported across all CAR $\mathrm{T}$ cell clinical trials, with an incidence as high as $74 \%$ to $100 \%$ for CD19-directed CAR T cells. ${ }^{33} 103-105$ CRS can present with a variety of symptoms. Mild symptoms of CRS include fever, headache, rash, arthralgia, and myalgia. More severe cases are characterized by hypotension that 
can progress to an uncontrolled systemic inflammatory response with vasopressor-requiring circulatory shock, vascular leakage, disseminated intravascular coagulation, and multiorgan system failure. ${ }^{100} 103$ 106-112

Several descriptions of management strategies for CAR $\mathrm{T}$ cell-associated CRS have been published, which generally encompass supportive care and anti-IL-6 therapies to break the cycle of inflammation. ${ }^{03} 109110113-115110$ CRS toxicity may be mitigated by modifying the dosing of CAR $\mathrm{T}$ cells to attenuate peak expansion and proliferation, as was demonstrated in a recent report using fractionated dosing scheme of infused CAR T cells that demonstrated high response rates with acceptable tolerability in adult patients with ALL. ${ }^{116}$

Neurotoxicity has been reported in nearly every study involving CD19-directed T cells, including CAR T cells and blinatumomab. In the TOWER trial evaluating blinatumomab for the treatment of patients with ALL, 25/267 (9.4\%) patients experienced neurotoxicities. ${ }^{20}$ Neurotoxicities were also observed in the ELIANA trial of tisagenlecleucel, where $40 \%$ of patients $(30 / 75)$ experienced an event of any grade, and $13 \%$ of patients $(10 / 75)$ experienced a grade 3 event. ${ }^{33}$ Risk factors for neurotoxicity after CAR $\mathrm{T}$ cell treatment include extramedullary disease younger age, pre-existing neurological comorbidities, higher total CAR T cell doses, early and/or severe CRS, and cytopenias. ${ }^{114} 117$ Unlike CRS, neurotoxicity secondary to CAR $\mathrm{T}$ cell treatment does not respond to tocilizumab. ${ }^{33} 117-120$

\section{Panel recommendations}

- For patients participating in clinical trials using CAR $\mathrm{T}$ cells, toxicity should be assessed and managed as per study protocols.

- Patients treated with CAR T cells or blinatumomab should be monitored vigilantly for signs of CRS and neurotoxicity including (but not limited to) fever, hypotension, and altered mental state.

- The management of CRS or neurotoxicity secondary to approved CAR T cell therapy or blinatumomab should follow established guidelines.

\section{PATIENT SUPPORT AND QUALITY OF LIFE (QOL) CONSIDERATIONS}

While immunotherapy may provide a significant and durable antitumor response for many patients, the appropriateness of any treatment option ultimately depends on patient-specific considerations. Although the likelihood for deep and durable response is the utmost priority in treatment selection, it is important to consider the potential effects on patient satisfaction and QoL for a planned intervention. Several analyses of QoL during chemotherapy in patients with acute leukemia have found that intensive induction regimens are linked to detrimental physical and psychological effects, such as fatigue, loss of physical function, and depression. ${ }^{121} 122$ However, several studies have also found that, in general, QoL improves significantly when patients are in remission. ${ }^{121} 122$
Immunotherapies offer the potential for prolonged remissions in some subsets of patients. Yet, although the side effects of immunotherapy might be more tolerable for patients than those that accompany cytotoxic drugs, the toxicities associated with immunotherapeutic approaches may be life-threatening in some cases; for example, CRS due to CAR T cell and BiTE therapies and VOD/SOS after some ADCs. Thorough patient education, as well as ongoing dialog among all members of a patient's care team, is critical to ensure that the individualized and unique aspects of immunotherapy are understood, as well as the importance of promptly reporting any toxicity.

Due to the rapidly evolving nature of the field, relatively few large-scale QoL assessments directly comparing immunotherapeutic approaches with SOC treatment for patients with acute leukemia have been completed. From the available literature, however, recently approved immunotherapies compare favorably with intensive chemotherapy and allo-HCT in terms of patient-reported outcomes and QoL.

An analysis of patient outcomes in the phase III TOWER study of blinatumomab in adults with $\mathrm{RR} \mathrm{Ph}-\mathrm{B}$-cell precursor ALL found patients who were treated with SOC chemotherapy $(\mathrm{n}=95)$ reported significant deteriorations in several functional measures (physical, role, and social) and symptoms as measured by the 30-item European Organization for Research and Treatment of Cancer Quality of Life Questionnaire (QLQ-C30) and markedly decreased overall global health status/QoL scores relative to blinatumomab. Furthermore, the time to clinically meaningful deterioration in HRQL or death was delayed for blinatumomab versus chemotherapy across all EORTC QLQ-C30 scales. ${ }^{123} \mathrm{n}$ the phase III INO-VATE trial, patients with RR B-ALL who received inotuzumab ozogamicin ${ }^{124}$ reported better QOL, functioning, and symptom scores (except for constipation and emotional functioning). ${ }^{124}$ Similarly, an analysis of 58 patients with RR B-ALL aged 8-23years treated with tisagenlecleucel in the phase II ELIANA trial demonstrated improvements in patient-reported QoL scores for all measures at month 3 after infusion with a mean change from baseline of 13.3 (95\% CI, 8.9 to 17.6) for the pediatric quality of life inventory (PedsQL) total score and 16.8 (95\% CI, 9.4 to 24.3) for the EQ-5D Visual Analogue Scale. ${ }^{20}$

Depending on the immunotherapeutic agent used, hospitalization and monitoring during dosing and in the subsequent weeks may be required, which can affect a patient's QoL and ability to work. For example, blinatumomab requires continuous intravenous infusion over 4 weeks and hospitalization is recommended for the first 9 days of the first cycle for RR disease and 3 days of hospitalization for cycle 1 in the MRD setting. Additionally, patients are advised to refrain from driving and engaging in hazardous occupations or operating heavy or potentially dangerous machinery while receiving blinatumomab. ${ }^{31}$ Tisagenlecleucel requires patients to stay within proximity of their treatment center for the first month 
after infusion and, patients must be monitored two to three times during the first 7 days after treatment. ${ }^{46}$

Financial distress related to cancer also takes a substantial toll on patient QoL. ${ }^{125}$ Immunotherapies for leukemia are expensive. Importantly, patients may incur additional expenses, such as transportation to and from the hospital or accommodations nearby during treatment, further highlighting that unequal access to these emerging therapies.

Despite high prices, immunotherapeutic agents fare favorably in cost-effectiveness analyses, offering significant gains in life years and QoL years (quality-adjusted life years (QALYs) ) for patients. A recent cost-effectiveness study of CAR T cell therapy versus SOC for pediatric patients with B-ALL found that tisagenlecleucel had a total discounted cost of US\$667,000 (including hospital stays and other expenses), with 10.34 discounted life years gained and 9.28 QALYs gained, which amounted to an incremental cost-effectiveness ratio of approximately US $\$ 42,000$ per life year gained and approximatelyUS\$46,000 per QALY gained compared with clofarabine. ${ }^{126}$ In adults with RR $\mathrm{Ph}-\mathrm{B}-\mathrm{ALL}$, blinatumomab was found to yield 1.92 additional life years and 1.64 additional quality-adjusted life years (QALYs) compared with SOC at an incremental cost of US $\$ 180,642$. The incremental cost-effectiveness ratio for blinatumomab vs SOC was estimated to be $\$ 110,108$ / QALY gained in the base case. ${ }^{127}$ In the UK, the National Institute for Health and Care Excellence estimated substantial improvement in survival with inotuzumab ozogamicin compared with SOC, providing an additional 5.2 life years and 2.2 QALYs. ${ }^{128}$ The deterministic incremental cost-effectiveness ratio was between $£ 33,749$ and $£ 37,497$ per quality-adjusted life-year gained compared with standard of care.

\section{Panel recommendations}

- Prior to being treated with immunotherapy, patients and caregivers should be educated about potential AEs and given clear instructions for call parameters for any toxicities.

- Study protocols for new, investigational agents should incorporate QoL assessment using validated tools.

\section{CONCLUSION}

Once almost universally fatal, the 5-year survival rate for acute leukemia has risen to $63 \%$ in the US. ${ }^{129}$ The advent of immunotherapy has expanded the available options in the treatment repertoire for acute leukemia, although progress has been slower in the AML setting. Every year, novel agents including BiTEs, CAR T cell therapies, and ADCs continue to demonstrate impressive response rates with favorable toxicity profiles across a variety of disease states. Despite these advances, many patients remain ineligible for immunotherapeutic treatments, and relapses after some of the newer modalities remain associated with a very poor prognosis. In the future, the indications for existing therapies are likely to continue to expand and novel agents with potentially distinct mechanisms of actions will be approved. Promising areas for future research in leukemia include improvements in CAR constructs and combining CAR $\mathrm{T}$ cell therapies with other immunotherapy approaches as well as the development of additional bispecific monoclonal antibodies. In AML specifically, there is great potential in efforts aimed at targeting novel proteins that might be more effective or more specific to early leukemia progenitors for novel antibodies such as CLL1, WT1, and PR1 as well as the development of CAR T cells for myeloid leukemias with 'off switches' to minimize long-term myelosuppression. Therefore, as the field continues to develop, these recommendations will be updated.

\section{Author affiliations}

${ }^{1}$ Department of Medicine, UPMC Hillman Cancer Center, University of Pittsburgh School of Medicine, Pittsburgh, Pennsylvania, USA

${ }^{2}$ Virginia Cancer Specialists, Fairfax, Virginia, USA

${ }^{3}$ Department of Pathology, University of Chicago, Chicago, Illinois, USA

${ }^{4}$ Stem Cell Allotransplantation Section, Hematology Branch, National Heart, Lung, and Blood Institute, National Institutes of Health, Bethesda, Maryland, USA

${ }^{5}$ Department of Medicine, Memorial Sloan Kettering Cancer Center, New York, New York, USA

${ }^{6}$ Department of Medicine, Division of Hematology/Oncology, Georgia Cancer Center, Augusta, Georgia, USA

${ }^{7}$ Division of Hematology, University Hospitals of Cleveland and Case Western Reserve University, Cleveland, Ohio, USA

${ }^{8} \mathrm{Hematologic}$ Malignancies Research Institute, City of Hope National Medical Center, Duarte, California, USA

${ }^{9}$ Sidney Kimmel Comprehensive Cancer Center, Johns Hopkins University School of Medicine, Baltimore, Maryland, USA

${ }^{10}$ Clinical Research Services, University of Pittsburgh Medical Center, Pittsburgh,

Pennsylvania, USA

${ }^{11}$ Investigational Drug Branch, Cancer Therapy Evaluation Program, National Cancer Institute, Bethesda, Maryland, USA

${ }^{12}$ Division of Hematology, Mayo Clinic, Rochester, Minnesota, USA

${ }^{13}$ Division of Hematology, Oncology and Transplantation, Masonic Cancer Center, University of Minnesota, Minneapolis, Minnesota, USA

${ }^{14}$ Center for Blood Disorders and Stem Cell Transplantation, Swedish Cancer Institute, Seattle, Washington, USA

${ }^{15}$ Department of Hematology and Medical Oncology, Winship Cancer Institute, Emory University, Atlanta, Georgia, USA

Correction notice This article has been corrected since it was published. A supplementary file was removed as it was incorrectly included in the article.

Acknowledgements The authors acknowledge SITC staff for their contributions includingPeter Intile, PhD, Sam Million-Weaver, PhD and Hiromi Sato, PhD for medical writing and editorial support and Angela Kilbert, Ben Labbe, PhD, and Lionel Lim for project management and assistance. Additionally, the authors wish to thank the society for supporting the manuscript development.

Contributors All authors served on the SITC Acute Leukemia Immunotherapy Guideline Expert Panel, drafted content, and provided critical review during the manuscript development. MMB and MST provided leadership as Chairs of the Expert Panel and provided guidance on the manuscript structure and content and thus are first and last authors. JB was the patient advocate representative. All authors have read and approved the final version of this manuscript.

Funding The authors have not declared a specific grant for this research from any funding agency in the public, commercial or not-for-profit sectors.

Competing interests RJB-Consulting fees: Gracell Bio; Grant Support, IP Rights \& Royalties: JUNO Therapeutics; JC—Consulting Fees: Pfizer, Novartis, Jazz, Takeda, Biopath Holdings, Daiichi; Contracted Research: Pfizer, Novartis, Jazz, Takeda, Daiichi, Merus, Amphivena, Sun Pharma; MDL—Advisory Board: Celgene, Pharmacyclics, Pfizer; SJF-Consulting Fees, IP Rights \& Royalties: Mustang Bio; EJF-Contracted Research, Consulting Fees, IP Rights, Royalties \& Ownership Interest: Cellunova LLC; MRL—Consulting Fees: Sanofi, NewLink Genetics; 
Contracted Research: Abbvie, Amgen, Astellas, Actinium, Novartis; JSM—Consulting Fees: Fate Therapeutics, GT Biopharma, Nektar, Onklmmune; Contracted Research, IP Rights \& Royalties: Fate Therapeutics, GT Biopharma; EKW—Consulting Fees, IP Rights \& Ownership Interest: Cambium Medical Technology. MMB, MST, IA, DAA, JB, JB, LJF, SDG, JMP—Nothing to disclose; SITC Staff: AK, BL, HS, LL, PI, SMW— Nothing to disclose

\section{Patient consent for publication Not required.}

Provenance and peer review Not commissioned; externally peer reviewed.

Open access This is an open access article distributed in accordance with the Creative Commons Attribution Non Commercial (CC BY-NC 4.0) license, which permits others to distribute, remix, adapt, build upon this work non-commercially, and license their derivative works on different terms, provided the original work is properly cited, appropriate credit is given, any changes made indicated, and the use is non-commercial. See http://creativecommons.org/licenses/by-nc/4.0/.

\section{REFERENCES}

1 Arber DA, Orazi A, Hasserjian R, et al. The 2016 revision to the World Health Organization classification of myeloid neoplasms and acute leukemia. Blood 2016;127:2391-405.

2 Siegel RL, Miller KD, Jemal A. Cancer statistics, 2020. CA Cancer J Clin 2020;70:7-30.

3 Bonaventure A, Harewood R, Stiller CA, et al. Worldwide comparison of survival from childhood leukaemia for 1995-2009, by subtype, age, and sex (CONCORD-2): a population-based study of individual data for 89828 children from 198 registries in 53 countries. Lancet Haematol 2017;4:e202-17.

4 Döhner H, Estey E, Grimwade D, et al. Diagnosis and management of AML in adults: 2017 ELN recommendations from an international expert panel. Blood 2017;129:424-47.

5 Tallman MS, Wang ES, Altman JK, et al. Acute myeloid leukemia, version 3.2019, NCCN clinical practice guidelines in oncology. $J$ Natl Compr Canc Netw 2019;17:721-49.

6 Arber DA, Borowitz MJ, Cessna M, et al. Initial diagnostic workup of acute leukemia: guideline from the College of American pathologists and the American Society of hematology. Arch Pathol Lab Med 2017;141:1342-93.

7 Patel JP, Gönen M, Figueroa ME, et al. Prognostic relevance of integrated genetic profiling in acute myeloid leukemia. $N$ Engl $\mathrm{J}$ Med 2012;366:1079-89.

8 Gupta V, Tallman MS, He W, et al. Comparable survival after HLAwell-matched unrelated or matched sibling donor transplantation for acute myeloid leukemia in first remission with unfavorable cytogenetics at diagnosis. Blood 2010;116:1839-48.

9 Koreth J, Schlenk R, Kopecky KJ, et al. Allogeneic stem cell transplantation for acute myeloid leukemia in first complete remission: systematic review and meta-analysis of prospective clinical trials. JAMA 2009;301:2349-61.

10 Litzow MR, Tarima S, Pérez WS, et al. Allogeneic transplantation for therapy-related myelodysplastic syndrome and acute myeloid leukemia. Blood 2010;115:1850-7.

11 Horowitz MM, Gale RP, Sondel PM, et al. Graft-versusleukemia reactions after bone marrow transplantation. Blood 1990;75:555-62.

12 Weiden PL, Flournoy N, Thomas ED, et al. Antileukemic effect of graft-versus-host disease in human recipients of allogeneic-marrow grafts. N Engl J Med 1979;300:1068-73.

13 Cornelissen JJ, Blaise D. Hematopoietic stem cell transplantation for patients with AML in first complete remission. Blood 2016;127:62-70.

14 Rashidi A, Walter RB, Tallman MS, et al. Maintenance therapy in acute myeloid leukemia: an evidence-based review of randomized trials. Blood 2016;128:763-73.

15 Maury S, Chevret S, Thomas X, et al. Rituximab in B-lineage adult acute lymphoblastic leukemia. N Engl J Med 2016;375:1044-53.

16 Brentjens RJ, Davila ML, Riviere I, et al. CD19-targeted T cells rapidly induce molecular remissions in adults with chemotherapyrefractory acute lymphoblastic leukemia. Sci Trans/ Med 2013;5:177ra38.

17 Boyiadzis MM, Dhodapkar MV, Brentjens RJ, et al. Chimeric antigen receptor (CAR) T therapies for the treatment of hematologic malignancies: clinical perspective and significance. J Immunother Cancer 2018;6:137.

18 Wei G, Wang J, Huang $\mathrm{H}$, et al. Novel immunotherapies for adult patients with B-lineage acute lymphoblastic leukemia. J Hematol Oncol 2017;10:150.
19 Fultang L, Panetti S, Ng M, et al. Mdsc targeting with Gemtuzumab ozogamicin restores $\mathrm{T}$ cell immunity and immunotherapy against cancers. EBioMedicine 2019;47:235-46.

20 Kantarjian H, Stein A, Gökbuget N, et al. Blinatumomab versus chemotherapy for advanced acute lymphoblastic leukemia. $N$ Engl J Med 2017;376:836-47.

21 Kantarjian HM, DeAngelo DJ, Stelljes M, et al. Inotuzumab Ozogamicin versus standard therapy for acute lymphoblastic leukemia. N Engl J Med 2016;375:740-53.

22 Boyiadzis M, Bishop MR, Abonour R, et al. The Society for Immunotherapy of Cancer consensus statement on immunotherapy for the treatment of hematologic malignancies: multiple myeloma, lymphoma, and acute leukemia. J Immunother Cancer 2016;4:90.

23 Graham R, Mancher M, Wolman DM, et alGraham R, Mancher $\mathrm{M}$, Wolman DM, et al, eds. Institute of medicine. clinical practice guidelines we can trust. Washington, DC: The National Academies Press, 2011: 290

24 de Haas V, Ismaila N, Advani A, et al. Initial diagnostic work-up of acute leukemia: ASCO clinical practice guideline endorsement of the College of American pathologists and American Society of hematology guideline. J Clin Oncol 2019;37:239-53.

25 Schuurhuis GJ, Heuser M, Freeman S, et al. Minimal/measurable residual disease in AML: a consensus document from the European LeukemiaNet MRD Working Party. Blood 2018;131:1275-91.

26 Hoelzer D, Bassan R, Dombret H, et al. Acute lymphoblastic leukaemia in adult patients: ESMO clinical practice guidelines for diagnosis, treatment and follow-up. Ann Oncol 2016;27:v69-82.

27 Percival M-E, Lai C, Estey E, et al. Bone marrow evaluation for diagnosis and monitoring of acute myeloid leukemia. Blood Rev 2017;31:185-92.

28 Fry TJ, Shah NN, Orentas RJ, et al. CD22-targeted CAR T cells induce remission in B-ALL that is naive or resistant to CD19targeted CAR immunotherapy. Nat Med 2018;24:20-8.

29 Rosenthal J, Naqvi AS, Luo M, et al. Heterogeneity of surface CD19 and CD22 expression in $\mathrm{B}$ lymphoblastic leukemia. Am J Hematol 2018;93:E352-5.

30 Pfizer. MYLOTARG perscribing information New York City, NY. Available: https://www.accessdata.fda.gov/drugsatfda_docs/label/ 2017/761060lbl.pdf

31 Amgen. BLINCYTO perscribing information thousand oaks. Available: https://pi.amgen.com/ /media/amgen/repositorysites/piamgen-com/blincyto/blincyto_pi_hcp_english.pdf

32 Gökbuget N, Dombret H, Bonifacio M, et al. Blinatumomab for minimal residual disease in adults with $\mathrm{B}$-cell precursor acute lymphoblastic leukemia. Blood 2018;131:1522-31.

33 Maude SL, Laetsch TW, Buechner J, et al. Tisagenlecleucel in children and young adults with B-cell lymphoblastic leukemia. $N$ Engl J Med 2018;378:439-48.

34 Gökbuget N, Dombret H, Giebel S, et al. Minimal residual disease level predicts outcome in adults with Ph-negative B-precursor acute lymphoblastic leukemia. Hematology 2019;24:337-48.

35 Jongen-Lavrencic M, Grob T, Hanekamp D, et al. Molecular minimal residual disease in acute myeloid leukemia. $N$ Engl J Med 2018;378:1189-99.

36 Berry DA, Zhou S, Higley $\mathrm{H}$, et al. Association of minimal residual disease with clinical outcome in pediatric and adult acute lymphoblastic leukemia: a meta-analysis. JAMA Oncol 2017;3:e170580.

37 Vey N, Davidson-Moncada JK, GL U, et al. A phase I, first-in-human study of MGD006/S80880 (CD123 X CD3 dart) in AML/MDS. Blood 2017;35:TPS7070-TPS.

38 Cortes JE, DeAngelo DJ, Erba HP, et al. Maturing clinical profile of IMGN779, a next-generation CD33-Targeting antibody-drug conjugate, in patients with relapsed or refractory acute myeloid leukemia. Blood 2018;132:26.

39 Brown PA, Shah B, Fathi A, et al. NCCN guidelines insights: acute lymphoblastic leukemia, version 1.2017. J Natl Compr Canc Netw 2017;15:1091-102.

40 Schuster SJ, Bishop MR, Tam C, et al. Sustained disease control for adult patients with relapsed or refractory diffuse large B-cell lymphoma: an updated analysis of Juliet, a global pivotal phase 2 trial of Tisagenlecleucel. Blood 2018;132:1684.

41 Goekbuget N, Dombret $\mathrm{H}$, Bonifacio M, et al. Blast: a confirmatory, single-arm, phase 2 study of Blinatumomab, a bispecific T-cell Engager $\left(\mathrm{BiTE}^{\circledR}\right)$ antibody construct, in patients with minimal residual disease B-Precursor acute lymphoblastic leukemia (all). Blood 2014;124:379.

42 Yurkiewicz IR, Muffly L, Liedtke M. Inotuzumab ozogamicin: a CD22 mAb-drug conjugate for adult relapsed or refractory B-cell precursor acute lymphoblastic leukemia. Drug Des Devel Ther 2018;12:2293-300. 
43 Pfizer. BESPONSA perscribing information New York City, NY. Available: https://www.accessdata.fda.gov/drugsatfda_docs/label/ 2017/761040s000lbl.pdf

44 O'Leary MC, Lu X, Huang Y, et al. Fda approval summary: Tisagenlecleucel for treatment of patients with relapsed or refractory B-cell precursor acute lymphoblastic leukemia. Clin Cancer Res 2019;25:1142-6.

45 Grupp SA, Maude SL, Rives S, et al. Updated analysis of the efficacy and safety of Tisagenlecleucel in pediatric and young adult patients with relapsed/refractory $(r / r)$ acute lymphoblastic leukemia. Blood 2018:132:895.

46 Novartis. Kymriah package insert. FDA US, 2017.

47 Bader $\mathrm{P}$, Hancock J, Kreyenberg $\mathrm{H}$, et al. Minimal residual disease (MRD) status prior to allogeneic stem cell transplantation is a powerful predictor for post-transplant outcome in children with all. Leukemia 2002;16:1668-72.

48 van Dongen JJM, van der Velden VHJ, Brüggemann $\mathrm{M}$, et al. Minimal residual disease diagnostics in acute lymphoblastic leukemia: need for sensitive, fast, and standardized technologies. Blood 2015;125:3996-4009.

49 Pulsipher MA, Carlson C, Langholz B, et al. IgH-V(D)J NGS-MRD measurement pre- and early post-allotransplant defines very lowand very high-risk ALL patients. Blood 2015;125:3501-8.

50 Hay KA, Gauthier J, Hirayama AV, et al. Factors associated with durable EFS in adult B-cell all patients achieving MRD-negative $\mathrm{Cr}$ after CD19 CAR T-cell therapy. Blood 2019;133:1652-63.

51 Hay KA, Turtle CJ. Chimeric antigen receptor (CAR) T cells: lessons learned from targeting of CD19 in B-cell malignancies. Drugs 2017:77:237-45.

52 Brown PA, Wieduwilt M, Logan A, et al. NCCN guidelines insights: acute lymphoblastic leukemia, version 1.2019 2019;17:414.

53 Chen Y, Cheng Y, Suo P, et al. Donor-Derived CD19-targeted T cell infusion induces minimal residual disease-negative remission in relapsed B-cell acute lymphoblastic leukaemia with no response to donor lymphocyte infusions after haploidentical haematopoietic stem cell transplantation. Br J Haematol 2017;179:598-605.

54 Kantarjian HM, DeAngelo DJ, Advani AS, et al. Hepatic adverse event profile of inotuzumab ozogamicin in adult patients with relapsed or refractory acute lymphoblastic leukaemia: results from the open-label, randomised, phase 3 INO-VATE study. Lancet Haematol 2017;4:e387-98.

55 Park JH, Rivière I, Gonen M, et al. Long-Term follow-up of CD19 CAR therapy in acute lymphoblastic leukemia. $N$ Engl $\mathrm{J} \mathrm{Med}$ 2018;378:449-59.

56 Davids MS, Kim HT, Bachireddy P, et al. Ipilimumab for patients with relapse after allogeneic transplantation. N Engl J Med 2016;375:143-53

57 ljaz A, Khan AY, Malik SU, et al. Significant risk of graft-versushost disease with exposure to checkpoint inhibitors before and after allogeneic transplantation. Biol Blood Marrow Transplant 2019;25:94-9.

58 Godwin CD, Gale RP, Walter RB. Gemtuzumab ozogamicin in acute myeloid leukemia. Leukemia 2017;31:1855-68.

59 Bross PF, Beitz J, Chen G, et al. Approval summary: gemtuzumab ozogamicin in relapsed acute myeloid leukemia. Clin Cancer Res 2001;7:1490-6.

60 Giles FJ, Kantarjian HM, Kornblau SM, et al. Mylotarg (gemtuzumab ozogamicin) therapy is associated with hepatic venoocclusive disease in patients who have not received stem cell transplantation. Cancer 2001;92:406-13.

61 Petersdorf SH, Kopecky KJ, Slovak M, et al. A phase 3 study of gemtuzumab ozogamicin during induction and postconsolidation therapy in younger patients with acute myeloid leukemia. Blood 2013;121:4854-60.

62 Hills RK, Castaigne S, Appelbaum FR, et al. Addition of gemtuzumab ozogamicin to induction chemotherapy in adult patients with acute myeloid leukaemia: a meta-analysis of individual patient data from randomised controlled trials. Lancet Oncol 2014:15:986-96.

63 Buckley SA, Wood BL, Othus M, et al. Minimal residual disease prior to allogeneic hematopoietic cell transplantation in acute myeloid leukemia: a meta-analysis. Haematologica 2017;102:865-73

64 Zahler S, Bhatia M, Ricci A, et al. A phase I study of ReducedIntensity conditioning and allogeneic stem cell transplantation followed by dose escalation of targeted consolidation immunotherapy with Gemtuzumab Ozogamicin in children and adolescents with CD33+ acute myeloid leukemia. Biol Blood Marrow Transplant 2016;22:698-704.
65 Toffalori C, Zito L, Gambacorta V, et al. Immune signature drives leukemia escape and relapse after hematopoietic cell transplantation. Nat Med 2019;25:603-11.

66 Christopher MJ, Petti AA, Rettig MP, et al. Immune escape of relapsed AML cells after allogeneic transplantation. N Engl J Med 2018;379:2330-41.

67 Jan M, Leventhal MJ, Morgan EA, et al. Recurrent genetic HLA loss in AML relapsed after matched unrelated allogeneic hematopoietic cell transplantation. Blood Adv 2019;3:2199-204.

68 Vago L, Perna SK, Zanussi M, et al. Loss of mismatched HLA in leukemia after stem-cell transplantation. $N$ Engl J Med 2009;361:478-88

69 Schmid C, Labopin M, Nagler A, et al. Donor lymphocyte infusion in the treatment of first hematological relapse after allogeneic stem-cell transplantation in adults with acute myeloid leukemia: a retrospective risk factors analysis and comparison with other strategies by the EBMT acute leukemia Working Party. JCO 2007;25:4938-45

70 Schroeder T, Czibere A, Platzbecker U, et al. Azacitidine and donor lymphocyte infusions as first salvage therapy for relapse of AML or MDS after allogeneic stem cell transplantation. Leukemia 2013;27:1229-35.

71 Liu L, Chang Y-J, Xu L-P, et al. Reversal of T cell exhaustion by the first donor lymphocyte infusion is associated with the persistently effective antileukemic responses in patients with relapsed AML after Allo-HSCT. Biol Blood Marrow Transplant 2018;24:1350-9.

72 Ueda M, El-Jurdi N, Cooper B, et al. Low-Dose azacitidine with DNMT1 level monitoring to treat post-transplantation acute myelogenous leukemia or myelodysplastic syndrome relapse. Biol Blood Marrow Transplant 2019;25:1122-7.

73 Craddock C, Jilani N, Siddique S, et al. Tolerability and clinical activity of post-transplantation azacitidine in patients allografted for acute myeloid leukemia treated on the RICAZA trial. Biol Blood Marrow Transplant 2016;22:385-90.

74 Thomas DA, O'Brien S, Faderl S, et al. Chemoimmunotherapy with a modified hyper-CVAD and rituximab regimen improves outcome in de novo Philadelphia chromosome-negative precursor B-lineage acute lymphoblastic leukemia. J Clin Oncol 2010;28:3880-9.

75 Guy DG, Uy GL. Bispecific antibodies for the treatment of acute myeloid leukemia. Curr Hematol Malig Rep 2018;13:417-25.

76 Ravandi F, Stein AS, Kantariian HM, et al. A phase 1 first-in-human study of AMG 330, an Anti-CD33 bispecific T-cell Engager (BiTE $®$ ) antibody construct, in relapsed/refractory acute myeloid leukemia (R/R AML). Blood 2018;132:25.

77 Westervelt P, Roboz GJ, Cortes JE, et al. Phase 1 first-in-human trial of AMV564, a bivalent bispecific (2x2) CD33/CD3 T-cell Engager, in patients with relapsed/refractory acute myeloid leukemia (AML). Blood 2018:132:1455.

78 Tomlinson BK, Reddy V, Berger MS, et al. Rapid reduction of peripheral blasts in older patients with refractory acute myeloid leukemia (AML) using reinduction with single agent anti-CD45 targeted iodine $\left({ }^{131} \mathrm{I}\right)$ apamistamab [lomab-B] radioimmunotherapy in the phase III SIERRA trial. JCO 2019;37:7048.

79 Daver NG, Erba HP, Papadantonakis N, et al. A phase I, first-inhuman study evaluating the safety and preliminary antileukemia activity of IMGN632, a novel CD123-Targeting antibody-drug conjugate, in patients with relapsed/refractory acute myeloid leukemia and other CD123-Positive hematologic malignancies. Blood 2018;132:27.

80 Narayan R, Blonquist TM, Emadi A, et al. A phase 1 study of the antibody-drug conjugate brentuximab vedotin with re-induction chemotherapy in patients with CD30-expressing relapsed/refractory acute myeloid leukemia. Cancer 2020;126:1264-73.

81 Webster J, Luskin MR, Prince GT, et al. Blinatumomab in combination with immune checkpoint inhibitors of PD-1 and CTLA4 in adult patients with relapsed/refractory (R/R) CD19 positive B-cell acute lymphoblastic leukemia (all): preliminary results of a phase I study. Blood 2018;132:557.

82 Daver N, Garcia-Manero G, Basu S, et al. Efficacy, safety, and biomarkers of response to azacitidine and nivolumab in relapsed/ refractory acute myeloid leukemia: a nonrandomized, open-label, phase II study. Cancer Discov 2019;9:370-83.

83 Daver N, Garcia-Manero G, Basu S, et al. Nivolumab (Nivo) with Azacytidine (aza) in patients (PTS) with relapsed acute myeloid leukemia (AML) or frontline elderly AML. Blood 2017;130:1345.

84 Ravandi F, Assi R, Daver N, et al. Idarubicin, cytarabine, and nivolumab in patients with newly diagnosed acute myeloid leukaemia or high-risk myelodysplastic syndrome: a single-arm, phase 2 study. Lancet Haematol 2019;6:e480-8. 
85 Zeidner JF, Vincent BG, Ivanova A, et al. Phase II study of high dose cytarabine followed by pembrolizumab in relapsed/refractory acute myeloid leukemia (AML). Blood 2017;130:1349.

86 Daver NG, Garcia-Manero G, Konopleva MY, et al. Azacitidine (aza) with nivolumab (Nivo), and aza with Nivo + ipilimumab (IPI) in relapsed/refractory acute myeloid leukemia: a Non-Randomized, prospective, phase 2 study. Blood 2019;134:830-.

87 Shah NN, Shalabi H, Yates B, et al. Abstract LB-146: phase I CD22 CAR T-cell trial updates. Cancer Res 2019;79:LB-146-LB-

88 Pan J, Niu Q, Deng B, et al. Cd22 CAR T-cell therapy in refractory or relapsed $B$ acute lymphoblastic leukemia. Leukemia 2019;33:2854-66.

89 Budde L, Song JY, Kim Y, et al. Remissions of acute myeloid leukemia and blastic plasmacytoid dendritic cell neoplasm following treatment with CD123-Specific CAR T cells: a first-in-human clinical trial. Blood 2017;130:811.

90 Bonini C, Ciceri F, Nagler A, et al. Infusion of donor lymphocytes genetically engineered to express the herpes simplex virus thymidine kinase (HSV-tk) suicide gene after haploidentical hematopoietic stem cell transplantation (HSCT): preliminary efficacy data from the randomized TK008 study. Blood 2014;124:2535

91 Romee R, Rosario M, Berrien-Elliott MM, et al. Cytokine-Induced memory-like natural killer cells exhibit enhanced responses against myeloid leukemia. Sci Transl Med 2016;8:357ra123.

92 Chapuis AG, Ragnarsson GB, Nguyen HN, et al. Transferred WT1reactive CD8+ T cells can mediate antileukemic activity and persist in post-transplant patients. Sci Transl Med 2013;5:174ra27.

93 Chapuis AG, Egan DN, Bar M, et al. T cell receptor gene therapy targeting WT1 prevents acute myeloid leukemia relapse posttransplant. Nat Med 2019;25:1064-72.

94 Shankar K, Capitini CM, Saha K. Genome engineering of induced pluripotent stem cells to manufacture natural killer cell therapies. Stem Cell Res Ther 2020;11:234.

95 Aldoss I, Forman SJ. How I treat adults with advanced acute lymphoblastic leukemia eligible for CD19-targeted immunotherapy. Blood 2020;135:804-13.

96 Zhao J, Song Y, Liu D. Clinical trials of dual-target CAR T cells, donor-derived CAR T cells, and universal CAR T cells for acute lymphoid leukemia. J Hematol Oncol 2019;12:17.

97 Gardner R, Annesley C, Finney O, et al. Early clinical experience of CD19 X CD22 dual specific CAR T cells for enhanced anti-leukemic targeting of acute lymphoblastic leukemia. Blood 2018;132:278.

98 Yang J, Li J, Zhang X, et al. A feasibility and safety study of CD19 and CD22 chimeric antigen receptors-modified T cell cocktail for therapy of B cell acute lymphoblastic leukemia. Blood 2018;132:277.

99 Puzanov I, Diab A, Abdallah K, et al. Managing toxicities associated with immune checkpoint inhibitors: consensus recommendations from the Society for Immunotherapy of Cancer (SITC) toxicity management Working group. J Immunother Cancer 2017;5:95

100 Lee DW, Santomasso BD, Locke FL, et al. ASTCT consensus grading for cytokine release syndrome and neurologic toxicity associated with immune effector cells. Biol Blood Marrow Transplant 2019;25:625-38.

101 Kebriaei P, Cutler C, de Lima M, et al. Management of important adverse events associated with inotuzumab ozogamicin: expert panel review. Bone Marrow Transplant 2018;53:449-56.

102 Stein AS, Schiller G, Benjamin R, et al. Neurologic adverse events in patients with relapsed/refractory acute lymphoblastic leukemia treated with blinatumomab: management and mitigating factors. Ann Hematol 2019;98:159-67.

103 Lee DW, Gardner R, Porter DL, et al. Current concepts in the diagnosis and management of cytokine release syndrome. Blood 2014;124:188-95.

104 Hay KA, Hanafi L-A, Li D, et al. Kinetics and biomarkers of severe cytokine release syndrome after CD19 chimeric antigen receptormodified T-cell therapy. Blood 2017;130:2295-306.

105 Schuster SJ, Bishop MR, Tam CS, et al. Tisagenlecleucel in adult relapsed or refractory diffuse large B-cell lymphoma. N Engl J Med 2019;380:45-56.

106 Acharya UH, Dhawale T, Yun S, et al. Management of cytokine release syndrome and neurotoxicity in chimeric antigen receptor (CAR) T cell therapy. Expert Rev Hematol 2019;12:195-205.

107 Shimabukuro-Vornhagen A, Gödel P, Subklewe M, et al. Cytokine release syndrome. J Immunother Cancer 2018;6:56.

108 Fishman JA, Hogan JI, Maus MV. Inflammatory and infectious syndromes associated with cancer immunotherapies. Clin Infect Dis 2019;69:909-20.

109 Frey N, Porter D. Cytokine release syndrome with chimeric antigen receptor T cell therapy. Biol Blood Marrow Transplant 2019;25:e123-7.
110 Porter D, Frey N, Wood PA, et al. Grading of cytokine release syndrome associated with the CAR T cell therapy tisagenlecleucel. $J$ Hematol Oncol 2018;11:35.

111 Riegler LL, Jones GP, Lee DW. Current approaches in the grading and management of cytokine release syndrome after chimeric antigen receptor T-cell therapy. Ther Clin Risk Manag 2019:15:323-35.

112 Titov A, Petukhov A, Staliarova A, et al. The biological basis and clinical symptoms of CAR-T therapy-associated toxicites. Cell Death Dis 2018:9:897.

113 Brudno JN, Kochenderfer JN. Toxicities of chimeric antigen receptor T cells: recognition and management. Blood 2016;127:3321-30.

114 Brudno JN, Kochenderfer JN. Recent advances in car T-cell toxicity: mechanisms, manifestations and management. Blood Rev 2019;34:45-55.

115 Neelapu SS, Tummala S, Kebriaei P, et al. Chimeric antigen receptor T-cell therapy - assessment and management of toxicities. Nat Rev Clin Oncol 2018;15:47-62.

116 Frey NV, Shaw PA, Hexner EO, et al. Optimizing chimeric antigen receptor T-cell therapy for adults with acute lymphoblastic leukemia. J Clin Oncol 2020;38:415-22.

117 Santomasso BD, Park JH, Salloum D, et al. Clinical and biological correlates of neurotoxicity associated with CAR T-cell therapy in patients with B-cell acute lymphoblastic leukemia. Cancer Discov 2018;8:958-71.

118 Gust J, Hay KA, Hanafi L-A, et al. Endothelial activation and blood-brain barrier disruption in neurotoxicity after adoptive immunotherapy with CD19 CAR-T cells. Cancer Discov 2017;7:1404-19.

119 Neelapu SS, Locke FL, Bartlett NL, et al. Axicabtagene Ciloleuce CAR T-cell therapy in refractory large B-cell lymphoma. $N$ Engl J Med 2017;377:2531-44.

120 Chen F, Teachey DT, Pequignot E, et al. Measuring IL-6 and SIL-6R in serum from patients treated with tocilizumab and/or siltuximab following CAR T cell therapy. J Immunol Methods 2016;434:1-8.

121 Leak Bryant A, Lee Walton A, Shaw-Kokot J, et al. Patient-Reported symptoms and quality of life in adults with acute leukemia: a systematic review. Oncol Nurs Forum 2015;42:E91-101.

122 Buckley SA, Kirtane K, Walter RB, et al. Patient-Reported outcomes in acute myeloid leukemia: where are we now? Blood Rev 2018:32:81-7.

123 Topp MS, Zimmerman Z, Cannell P, et al. Health-Related quality of life in adults with relapsed/refractory acute lymphoblastic leukemia treated with blinatumomab. Blood 2018;131:2906-14.

124 Kantarjian HM, Su Y, Jabbour EJ, et al. Patient-Reported outcomes from a phase 3 randomized controlled trial of inotuzumab ozogamicin versus standard therapy for relapsed/refractory acute lymphoblastic leukemia. Cancer 2018;124:2151-60.

125 Tran G, Zafar SY. Financial toxicity and implications for cancer care in the era of molecular and immune therapies. Ann Trans/ Med 2018:6:166.

126 Whittington MD, McQueen RB, Ollendorf DA, et al. Long-Term survival and value of chimeric antigen receptor T-cell therapy for pediatric patients with relapsed or refractory leukemia. JAMA Pediatr 2018;172:1161-8.

127 Delea TE, Amdahl J, Boyko D, et al. Cost-Effectiveness of blinatumomab versus salvage chemotherapy in relapsed or refractory Philadelphia-chromosome-negative B-precursor acute lymphoblastic leukemia from a US payer perspective. J Med Econ 2017;20:911-22.

128 Cox E, Wade R, Peron M, et al. The clinical and cost effectiveness of Inotuzumab Ozogamicin for the treatment of adult relapsed or refractory B-cell acute lymphoblastic leukaemia: an evidence review group evaluation of a NICE single technology appraisal. Pharmacoeconomics 2019;37:1081-91.

129 Cronin KA, Lake AJ, Scott S, et al. Annual report to the nation on the status of cancer, part I: National cancer statistics. Cancer 2018;124:2785-800.

130 Zhu M, Wu B, Brandl C, et al. Blinatumomab, a Bispecific T-cell Engager (BiTE(囚)) for CD-19 Targeted Cancer Immunotherapy: Clinical Pharmacology and Its Implications. Clin Pharmacokinet 2016;55:1271-88.

131 Stein AS, Larson RA, Schuh AC, et al. Exposure-adjusted adverse events comparing blinatumomab with chemotherapy in advanced acute lymphoblastic leukemia. Blood Adv 2018;2:1522-31.

132 Zhu M, Kratzer A, Johnson J, et al. Blinatumomab pharmacodynamics and exposure-response relationships in relapsed/refractory acute lymphoblastic leukemia. J Clin Pharmacol 2018;58:168-79.

133 Barlev A, Lin VW, Katz A, et al. Estimating long-term surviva of adults with Philadelphia chromosome-negative relapsed/ 
refractory B-Precursor acute lymphoblastic leukemia treated with Blinatumomab using historical data. Adv Ther 2017;34:148-55.

134 Topp MS, Gökbuget N, Stein AS, et al. Safety and activity of blinatumomab for adult patients with relapsed or refractory Bprecursor acute lymphoblastic leukaemia: a multicentre, single-arm, phase 2 study. Lancet Oncol 2015;16:57-66.

135 Martinelli G, Boissel N, Chevallier P, et al. Complete hematologic and molecular response in adult patients with relapsed/ refractory Philadelphia chromosome-positive B-Precursor acute lymphoblastic leukemia following treatment with Blinatumomab: results from a phase II, single-arm, multicenter study. J Clin Oncol 2017;35:1795-802.

136 von Stackelberg A, Locatelli F, Zugmaier G, et al. Phase I/Phase II study of Blinatumomab in pediatric patients with relapsed/refractory acute lymphoblastic leukemia. J Clin Oncol 2016;34:4381-9.

137 Castaigne S, Pautas C, Terré C, et al. Effect of gemtuzumab ozogamicin on survival of adult patients with de-novo acute myeloid leukaemia (ALFA-0701): a randomised, open-label, phase 3 study. Lancet 2012;379:1508-16.
138 Lambert J, Pautas C, Terré C, et al. Gemtuzumab ozogamicin for de novo acute myeloid leukemia: final efficacy and safety updates from the open-label, phase III ALFA-0701 trial. Haematologica 2019;104:113-9.

139 Amadori S, Suciu S, Selleslag D, et al. Gemtuzumab Ozogamicin versus best supportive care in older patients with newly diagnosed acute myeloid leukemia unsuitable for intensive chemotherapy: results of the randomized phase III EORTC-GIMEMA AML-19 trial. J Clin Oncol 2016;34:972-9.

140 Taksin A-L, Legrand O, Raffoux E, et al. High efficacy and safety profile of fractionated doses of Mylotarg as induction therapy in patients with relapsed acute myeloblastic leukemia: a prospective study of the alfa group. Leukemia 2007;21:66-71.

141 Gamis AS, Alonzo TA, Meshinchi S, et al. Gemtuzumab ozogamicin in children and adolescents with de novo acute myeloid leukemia improves event-free survival by reducing relapse risk: results from the randomized phase III Children's Oncology Group trial AAML0531. J Clin Oncol 2014;32:3021-32. 